\title{
PAB3D: Its History in the Use of Turbulence Models in the Simulation of Jet and Nozzle Flows
}

\author{
Khaled S. Abdol-Hamid ${ }^{1}$, S. Paul $\mathrm{Pao}^{2}$, Craig A. Hunter3, Karen A. Deere ${ }^{4}$ \\ NASA Langley Research Center, Hampton, VA 23681 \\ Steven J. Massey ${ }^{5}$ \\ Eagle Aeronautics, Hampton, VA 23666 \\ and \\ Alaa Elmiligui ${ }^{6}$ \\ AS\&M, Inc., Hampton, VA 23666
}

\begin{abstract}
This is a review paper for PAB3D's history in the implementation of turbulence models for simulating jet and nozzle flows. We describe different turbulence models used in the simulation of subsonic and supersonic jet and nozzle flows. The time-averaged simulations use modified linear or nonlinear two-equation models to account for supersonic flow as well as high temperature mixing. Two multiscale-type turbulence models are used for unsteady flow simulations. These models require modifications to the Reynolds Averaged NavierStokes (RANS) equations. The first scheme is a hybrid RANS/LES model utilizing the twoequation (k- $\varepsilon$ ) model with a RANS/LES transition function, dependent on grid spacing and the computed turbulence length scale. The second scheme is a modified version of the partially averaged Navier-Stokes (PANS) formulation. All of these models are implemented in the three-dimensional Navier-Stokes code PAB3D. This paper discusses computational methods, code implementation, computed results for a wide range of nozzle configurations at various operating conditions, and comparisons with available experimental data. Very good agreement is shown between the numerical solutions and available experimental data over a wide range of operating conditions.
\end{abstract}

\section{Introduction}

$\mathrm{K}$ NOWLEDGE of jet mixing and nozzle aerodynamics is vital to several areas of commercial and military aircraft design, such as propulsion efficiency, propulsion integration, aeroacoustics, and jet interaction with aircraft structures. Initial jet flow conditions are determined by nozzle exit pressure, temperature, Mach number, and nozzle geometry. Once the exhaust flow leaves the nozzle, the jet flow forms a free shear layer. The action of turbulence dominates flow development farther downstream. As such, jet flow properties are difficult to measure or predict analytically. When Ludwig Prandtl introduced his mixing length hypothesis for turbulent flows 100 years ago, a brief analysis of a fully mixed jet was given as an example. For axisymmetric and two-dimensional jet flows, early analyses of mixing behavior were based mainly on this mixing length hypothesis and one-dimensional momentum theory (1-4). Mean flow properties for axisymmetric jets derived from these analytical models compared well with experimental measurements of jets at low subsonic speeds. However, data from jet flow measurements in the high subsonic and supersonic speed ranges (ref. 5) indicated significant departure from the results obtained by using one dimensional momentum theory.

Jet and nozzle flow contain rich combinations of flow interactions and flow physics. These combinations include turbulent mixing as well as temperature and compressibility effects. Other factors may include chemical reactions or

\footnotetext{
${ }^{1}$ Senior Research Scientist, Configuration Aerodynamics Branch, M.S. 499, NASA/LaRC, Hampton, VA 23681, Associate Fellow AIAA.

${ }^{2}$ Senior Research Scientist, Configuration Aerodynamics Branch, M.S. 499, NASA/LaRC, Hampton, VA 23681, Associate Fellow AIAA.

${ }^{3}$ Aerospace Engineer, Configuration Aerodynamics Branch, M.S. 499, NASA/LaRC, Hampton, VA 23681, AIAA Member.

${ }^{4}$ Aerospace Engineer, Configuration Aerodynamics Branch, M.S. 499, NASA/LaRC, Hampton, VA 23681, AIAA Member.

${ }^{5}$ Senior Research Scientist, Eagle Aeronautics, Inc., 13 W. Mercury Blvd., Hampton, VA 23669 AIAA Member.

${ }^{6}$ Senior Research Scientist, AS\&M, Inc., 107 Research Drive, Hampton, VA 23666, AIAA Member
} 
shear layer instability. The main flow physics feature in the subsonic jet flow is shear layer development along the streamwise direction. The static pressure value is almost the same as the ambient pressure. In the absence of a pressure gradient, no significant inviscid flow feature will appear in a subsonic jet. According to reported experimental measurements, all turbulent axisymmetric subsonic cold jets below Mach 0.6 are similar if the flow variables are normalized by jet density and nozzle-exit velocity.

On the other hand, supersonic jet flow features can be very complex. Because of the supersonic nozzle exit Mach number, a shock will form at the nozzle lip and the jet exit pressure can differ from the ambient pressure. This pressure difference between the jet and the ambient fluid must be resolved locally either across an oblique shock, by a prominent streamline curvature at the jet boundary, or both. A Mach disk can also form inside the jet. In addition, shocks initiated near the nozzle exit may reflect repeatedly at the sonic line in the shear layer downstream from the nozzle exit. Although the turbulence interacts with shocks in the jet, the position of the reflected shock depends mainly on the location of the sonic line in the turbulent shear layer. Such interdependence of flow interactions can become very complex.

Earlier jet flow analysis codes, with or without chemical interactions included, were formulated with simplified assumptions of the Navier-Stokes equations and the turbulence model to provide the best jet flow simulation within modest limits of computing resources available during this time period. Analytical methods and simulation codes developed by this approach have been successfully applied to problems in air-breathing engine development, acoustics, and rocket propulsion. (6-12) However, there are some drawbacks to this approach. First, simplified assumptions are often difficult to justify. Second, application of the simplified formulations is limited to just the jet flow. These formulations are therefore difficult to integrate with computational codes for airframe aerodynamics when propulsion airframe integration analysis is required. It is preferable in such cases to perform the analysis with the three-dimensional Navier-Stokes equations without empirical assumptions for jet flow alone.

Large temperature and pressure fluctuations have a profound effect on turbulence development in nozzle and jet flow. While several models have been developed to account for the effect of pressure fluctuations (compressibility correction models), very little has been done to account for large temperature fluctuations. This has led to poor CFD prediction of non-isothermal flows. For high-temperature jet flow, standard turbulence models lack the ability to predict the observed increase in growth rate of a mixing layer [13-14]. Several researchers [15-20] have modified one or more terms of the transport equations to obtain better agreement in high temperature flows. These modifications affect, directly or indirectly, the closure terms of the turbulent heat flux $\left(\rho \overline{u_{i} \theta}\right)$ and stresses $\left(\rho \overline{u_{i} u_{j}}\right)$. Theis and Tam [15] changed several coefficients in the turbulent transport equations. However, such extensive modifications of model coefficients completely change the characteristics of the equations and may cause deficiencies in flow prediction accuracy, problems for which these turbulence models were originally designed. Other attempts to sensitize the turbulence model to temperature fluctuations involve more sophisticated closure for the turbulent heat flux term appearing in the average energy equation [16-18]. Explicit algebraic nonlinear heat flux models have also been tested for this purpose. These models have been successful in some fully-developed high temperature turbulent flows. A simpler approach was to model the value of $\mathrm{C}_{\mu}$ as a function of the total temperature gradient in the flow [21].

For general use of steady-state jet flow simulation, some basic requirements must be met. The Navier-Stokes code should be upwind biased to capture shocks and other jet flow discontinuities. The code should also be fully three-dimensional in space because the relations between turbulent kinetic energy and Reynolds stresses are basically three-dimensional. The turbulence model should be capable of providing a time scale and a consistent description of the production and transport properties of turbulent kinetic energy. Therefore, at least a two-equation turbulence closure model is required. Many upwind-biased three-dimensional Navier-Stokes codes are available that meet the jet and nozzle flow simulation requirement. However, the availability of codes with a robust two-equation turbulence model in this class is limited. The PAB3D code has demonstrated the feasibility of establishing a unified method for subsonic and supersonic jet analysis with a general-purpose, three-dimensional Navier-Stokes code.

PAB3D code was developed to obtain numerical solutions to the Reynolds Averaged Navier-Stokes equations in three-dimensional spatial domain. The main solver algorithm is the upwind Roe scheme, for which the numerical dissipation is small. The Jones-Launder (22) two-equation $k-\varepsilon$ turbulence closure model is used as the basis for all the corrections added to enhance simulation accuracy for a wide range of nozzle shapes and jet flows. This approach is chosen for jet flow analysis because it is consistent in tracking production and transport properties of turbulence kinetic energy and dissipation scale length in the shear flow. In the Jones-Launder $k-\varepsilon$ turbulence model, several empirical constants are required. Only the published values for these constants are implemented in the PAB3D code. These values are fixed for all computational applications of the PAB3D code. The final turbulence model formulation used in PAB3D contains the following major modifications: 
1- Near wall modification

2- High temperature correction for hot jet

3- Compressibility correction for supersonic mixing layer

4- Algebraic Reynolds Stress for flow with separation

This modified turbulence model reverts back to the standard k- $\varepsilon$ model in the flow regions where there is no need for any of these corrections.

The limited capability of the Reynolds Averaged Navier-Stokes (RANS) approach, combined with eddyviscosity turbulence models to simulate unsteady and complex flows, has been known for some time. The RANS approach assumes that most of the energy is modeled through the turbulence transport equations and is resolved in the grid. RANS overpredicts the eddy viscosity, which results in excessive damping of unsteady motion. Consequently, the eddy viscosity attains un-physically large values due to unresolved scales, and suppresses most temporal and spatial fluctuations in the resolved flow field. Among several methods, the Detached Eddy Simulations (DES) [23], the hybrid Large Eddy Simulation (LES) [24-25], the Limited Numerical Scheme (LNS) [26], and the Partial Averaged Navier-Stokes (PANS) [27], provide the mechanisms needed to satisfy this requirement. AbdolHamid and Girimaji [28] explored a new approach to improve the accuracy and robustness of PANS in creating a simulation of an unsteady flow field. They accomplished this through the development and implementation of a twostage procedure to efficiently estimate the level of scale resolution possible for a given flow on a given grid for PANS and other hybrid models.

This paper describes the history of development of the PAB3D CFD code related to the application of turbulence models to jet and nozzle flows, and gives the complete description of turbulence models used in these simulations. Several categories of jet flow computation and nozzle configuration [28-64] are briefly described separately in the section "PAB3D History of Jet and Nozzle Simulations." This covers 17 years of the continuous development of PAB3D.

\section{PAB3D History of Development}

PAB3D is a structured, multiblock, parallel, implicit, finite-volume solver of the three-dimensional Reynolds Averaged Navier-Stokes (RANS) equations, and advanced turbulence models are available in the code. PAB3D is widely used for internal and external flow applications by NASA and by the US aerospace industry. PAB3D is one of the few codes available today that uses advanced turbulence models in the simulation of complex compressible three-dimensional flows. PAB3D developments and applications are documented in over 100 articles. References [21, 28, and 29-33] describe some of the major developments in the last 17 years. Some of the capabilities of PAB3D are listed below:

$>$ 3-D RANS/URANS/SMS upwind solver:

- Multiple flow solver (three factor, two factor, and diagonalization)

- Up to third order in space

- $\quad$ Up to second order in time

$>$ Linear two-equation models with several options: -

- Compressibility correction for high speed flow

- Near wall correction

- Temperature correction for high temperature jet flow

- Up to third order in space

- $\quad$ Up to second order in time

$>$ Several algebraic Reynolds stress models

> Tripping option for forced transition from laminar to turbulent flow

$>$ Multi-scale-type (hybrid) turbulence models: URANS/LES and PANS

$>$ Steady and unsteady flow boundary conditions

$>$ Modular multi-block structured with user options selectable for each block:

- Directional grid sequencing

- Turbulence Model options

- Scheme choice including limiter and order

- Viscous terms from simplified to fully coupled

- $\quad$ Number of iterations $\geq 0$ (effectively turn block on and off)

$>$ In-code calculations of integrated forces, moments, and flux quantities 


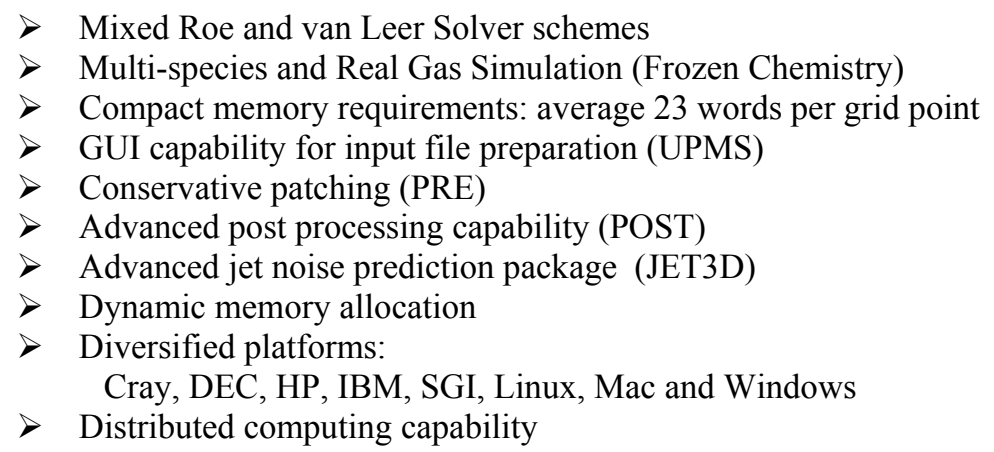

PAB3D has always been one of the first advanced CFD codes to implement and develop the latest numerical schemes, turbulence models, and boundary conditions to enhance its capabilities. Here are some of these examples:

1- $\quad$ Space Marching Scheme [29], 1989

2- Multiblock approach [29], 1989

3- Two-equation turbulence models [12 and 41], 1990

4- Compressibility corrections [38], 1991

5- Algebraic Reynolds Stress [34], 1994

6- High temperature correction [21], 2003

7- Hybrid methods [28], 2004

The governing equations of the RANS formulation include the conservation equations for mass, momentum, energy, and the equation of state. In the present paper, we use the perfect gas law to represent air properties, and use the eddy viscosity and nonlinear concepts to model Reynolds stresses. The mass, momentum, and energy conservation equations of the RANS equations can be written in a conservative form as follows:

$$
\begin{aligned}
& \frac{\partial \rho}{\partial t}+\frac{\partial \rho u_{i}}{\partial x_{i}}=0 \\
& \frac{\partial \rho u_{i}}{\partial t}+\frac{\partial\left(\rho u_{i} u_{j}+p \delta_{i j}\right)}{\partial x_{j}}=\frac{\partial\left(\tau_{i j}-\rho \overline{u_{i} u_{j}}\right)}{\partial x_{j}} \\
& \frac{\partial \rho e_{0}}{\partial t}+\frac{\partial\left(\rho e_{0} u_{i}+p u_{i}\right)}{\partial x_{i}}=\frac{\partial\left(\tau_{i j} u_{j}-\rho \overline{u_{i} u_{j}} u_{j}\right)}{\partial x_{i}}-\frac{\partial\left(q_{i}+C_{p} \rho \overline{u_{i} \theta}\right)}{\partial x_{i}}+\frac{\partial}{\partial x_{i}}\left[\rho\left(v_{l}+\frac{v_{t}}{\bar{\sigma}_{k}}\right) \frac{\partial k}{\partial x_{i}}\right]
\end{aligned}
$$

\section{A. RANS Closure}

To close the RANS equations, the two-equation $(\mathrm{k} \varepsilon)$ turbulence model is used:

$$
\begin{aligned}
& \frac{\partial \rho k}{\partial t}+\frac{\partial \rho u_{i} k}{\partial x_{i}}=-\rho \overline{u_{i} u_{j}} \frac{\partial u_{j}}{\partial x_{i}}+\frac{\partial}{\partial x_{i}}\left[\rho\left(v_{l}+\frac{c_{\mu} k^{2}}{\bar{\sigma}_{k} \varepsilon}\right) \frac{\partial k}{\partial x_{i}}\right]-\rho \tilde{\varepsilon} \\
& \frac{\partial \rho \varepsilon}{\partial t}+\frac{\partial \rho u_{i} \varepsilon}{\partial x_{i}}=-C_{\varepsilon 1} \rho \overline{u_{i} u_{j}} \frac{\partial u_{j}}{\partial x_{i}} \frac{\varepsilon}{k}+\frac{\partial}{\partial x_{i}}\left[\rho\left(v_{l}+\frac{c_{\mu} k^{2}}{\bar{\sigma}_{\varepsilon} \varepsilon}\right) \frac{\partial \varepsilon}{\partial x_{i}}\right]-f_{2} \bar{C}_{\varepsilon 2} \rho \frac{\varepsilon}{k}\left[\varepsilon-2 v_{l}\left(\frac{\partial \sqrt{k}}{\partial \eta}\right)^{2}\right] \\
C_{\mu}= & 0.09, C_{\varepsilon 1}=1.44 \\
\bar{\sigma}_{k}= & \sigma_{k}=1.4, \bar{\sigma}_{\varepsilon}=\sigma_{\varepsilon}=1 \text { and } \overline{C_{\varepsilon 2}}=C_{\varepsilon 2}=1.92
\end{aligned}
$$

The turbulent stress components are formulated as: 
$-\rho \overline{u_{i} u_{j}}=\tau_{i j}^{L}+\tau_{i j}^{N L}$

The linear contribution to the stress is

$\tau_{i j}^{L}=-2 \rho v_{t} S_{i j}+\frac{2}{3} \delta_{i j} \rho k$

where, $S_{i j}=\frac{1}{2}\left\lfloor\frac{\partial u_{i}}{\partial x_{j}}+\frac{\partial u_{j}}{\partial x_{i}}\right\rfloor-\frac{1}{3} \delta_{i j} \frac{\partial u_{k}}{\partial x_{k}}$

For the purpose of this paper, we will define RANS turbulent viscosity as

$$
v_{t}^{R A N S}=f_{\mu} C_{\mu}^{*} \frac{k^{2}}{\varepsilon}
$$

In the case of linear RANS simulation

$$
v_{t}=v_{t}^{R A N S} \text { and } C_{\mu}^{*}=0.09
$$

\section{Compressibility correction}

PAB3D has several compressibility corrections. In this paper, we will show results based on Sarkar's compressibility correction.

$$
\tilde{\varepsilon}=\varepsilon\left(1+M_{\tau}^{2}\right)
$$

Where is turbulent Mach number is defined as, $M_{\tau}=\sqrt{\frac{3 k}{2 a}}$

\section{Near wall correction}

PAB3D has several near wall corrections; the most used correction is based on Launder and Sharma defined as:

$$
f_{\mu}=\exp \left\lfloor\frac{-3.41}{\left(1+\frac{R_{T}}{50}\right)^{2}}\right\rfloor, R_{T}=\frac{k^{2}}{v_{l} \varepsilon}, f_{2}=1-0.3 \exp \left(-R_{T}^{2}\right)
$$

The boundary conditions for $\mathrm{k}$ and $\varepsilon$ at the wall are:

$$
\mathrm{k}_{\mathrm{wall}}=0 \text { and } \varepsilon_{\text {wall }}=2 v_{l}\left(\frac{\partial \sqrt{k}}{\partial n}\right)^{2}
$$

\section{High temperature correction}

In most applications, we use the Simple Eddy Diffusivity (SED) approach, which is based on the Boussinesq viscosity model is used. This approach is used to model all the scalar diffusion terms appearing in the RANS and standard k- $\varepsilon$ equations. For the heat flux term, the SED is written as follows:

$$
\rho \overline{u_{i} \theta}=-\frac{\rho v_{t}}{\sigma_{\tau}} \frac{\partial T}{\partial x_{i}} \quad \text { and } \quad \sigma_{\tau}=0.9
$$

For high temperature jet flow, we use the variable $\mathrm{C}_{\mu}$ developed by Abdol-Hamid et. al. [21] is used as follows: 


$$
\begin{aligned}
C_{\mu} & =0.09 C_{T} \\
C_{T} & =\left[1+\frac{T_{g}^{3}}{0.041+f\left(M_{\tau}\right)}\right]
\end{aligned}
$$

where,

$$
\begin{aligned}
& f\left(M_{\tau}\right)=\left(M_{\tau}^{2}-M_{\tau 0}^{2}\right) H\left(M_{\tau}-M_{\tau 0}\right), \\
& T_{g}=\nabla\left(T_{t}\right)\left(k^{3 / 2} / \varepsilon\right) / T_{t} \\
& \nabla\left(T_{t}\right)=\sqrt{\left(\frac{\partial T_{t}}{\partial x_{i}}\right)^{2}}
\end{aligned}
$$

\section{Algebraic Reynolds Stress}

$C_{\mu}^{*}$ is 0.09 for the linear model and is a function of vorticity and strain tensors for the nonlinear models. In the SZL nonlinear model [35], the turbulent stresses are given by:

$$
-\overline{u_{i} u_{j}}=2 v_{t} S_{i j}-\frac{2}{3} \delta_{i j} k-2 \beta \frac{k^{3}}{\varepsilon^{2}}\left(W_{i k} S_{k j}-S_{i k} W_{k j}\right)
$$

Stresses in the Girimaji nonlinear model [35] are given by:

$-\overline{u_{i} u_{j}}=2 v_{t} S_{i j}-\frac{2}{3} \delta_{i j} k-2 C_{\mu}^{*} \frac{k^{3}}{\varepsilon^{2}}\left[-G_{2}\left(W_{i k} \bar{S}_{k j}-\bar{S}_{i k} W_{k j}\right)+G_{3}\left(\bar{S}_{i k} \bar{S}_{k j}-\frac{1}{3} \bar{S}_{m n} \bar{S}_{m n} \delta_{i j}\right)\right]$

where

$$
\begin{gathered}
W_{i j}=\frac{1}{2}\left(\frac{\partial u_{i}}{\partial x_{j}}-\frac{\partial u_{j}}{\partial x_{i}}\right) \\
\bar{S}_{i j}=\frac{1}{2}\left[\frac{\partial u_{i}}{\partial x_{j}}+\frac{\partial u_{j}}{\partial x_{i}}\right]
\end{gathered}
$$

A compilation of the parameters used in the turbulence models can be found in the Appendix.

\section{B. Multiscale Approaches}

\section{Two-Stage PANS Approach}

The PANS model [27] was developed to overcome the grid dependency associated with the use of other Hybrid Turbulence Models (HTM). In its original form, PANS replaces the two-equation turbulence model by solving for the unresolved kinetic energy $\mathrm{k}_{\mathrm{u}}$ and the dissipation $\varepsilon_{\mathrm{u}}$. The $\mathrm{k}_{\mathrm{u}}$ equation is identical to the original $\mathrm{k}$ equation. In the $\varepsilon$ equation (equation 2), the following coefficients are used to change the two-equation model to the Hybrid Turbulence Model (HTM), which becomes known as the PANS formulation through the following changes:

$$
\begin{aligned}
& \tilde{C}_{\varepsilon 2}=\frac{f_{k}}{f_{\varepsilon}}\left(C_{\varepsilon 2}-C_{\varepsilon 1}\right)+C_{\varepsilon 1} \\
& \bar{\sigma}_{k}=\frac{f_{k}^{2}}{f_{\varepsilon}} \sigma_{k} \text { and } \bar{\sigma}_{\varepsilon}=\frac{f_{k}^{2}}{f_{\varepsilon}} \sigma_{\varepsilon}
\end{aligned}
$$

where 


$$
f_{k}=\frac{k_{u}}{k} \text { and } \quad f_{\varepsilon}=\frac{\varepsilon_{u}}{\varepsilon}
$$

represent the ratios of the unresolved kinetic energy and dissipation to the total kinetic energy and dissipation, respectively. It is only natural to use $\left(f_{k}, f_{\varepsilon}\right)$ to quantify the PANS filter with respect to RANS. Therefore, $\left(f_{k}, f_{\varepsilon}\right)$ are used as the resolution control parameters for PANS. Physics of turbulence dictates that:

$$
\text { (DNS) } 0 \leq f_{k} \leq f_{\varepsilon} \leq 1 \quad(\text { RANS })
$$

The original formulation [5] uses constant values for the unresolved kinetic energy parameter $\left(f_{\mathrm{k}}\right)$ and unresolved dissipation rate parameter $\left(f_{\varepsilon}\right)$. The users will select values for these parameters and refine the grid until the flow solution converges toward a solution target. This could be very time-consuming for resolving complex threedimensional flows. In the present paper, we will discuss an approach to define the unresolved kinetic energy parameter. Abdol-Hamid and Girimaji [28] introduced a two-stage approach to estimate the values of the unresolved kinetic energy parameter. Here, we will highlight the basic concepts of this approach. Based on a simple dimensional analysis, we assume that the turbulent viscosity may be related to the total kinetic energy $(\mathrm{k}), \varepsilon, \mathrm{S}$ and $\Delta$ as:

$$
v_{t} \approx \frac{k^{2}}{\varepsilon} \approx \Delta^{2} S \approx \Delta^{2} \frac{\varepsilon}{k}
$$

which leads to

$$
f_{k}^{3} k^{3} \approx \Delta^{2} \frac{k^{3}}{L^{2}}
$$

Hence,

$$
f_{k}=C_{h}\left[\frac{1}{\lambda}\right]^{2 / 3}, \lambda=\frac{L}{\Delta}, \quad L=\frac{k^{3 / 2}}{\varepsilon}
$$

$\mathrm{C}_{\mathrm{h}}$ is a model coefficient, which needs to be calibrated. In the present paper, a value of one will be used to evaluate the model. The guidelines, to be followed for the sequential two-stage procedure at this phase of methods development, are completely dependent upon flow complexity. Generally speaking, the first stage is a RANS flow simulation where the solution serves as the basis to estimate the $\left(f_{k}, f_{\varepsilon}\right)$ parameters for each grid cell. By using this fixed $\left(f_{k}, f_{\varepsilon}\right)$ distribution over the grid, one would then conduct an unsteady calculation by preferably using a high-order scheme and one of the hybrid solver models. An example is demonstrated in the "Unsteady Jet Simulation" section near the end of this paper.

\section{Hybrid RANS/LES Approach}

Nichols and Nelson [37] give an example of a hybrid RANS/LES turbulence model. This method was implemented in conjunction with Menter's SST two-equation turbulence model and is termed a multi-scale (MS) model. In the present paper, this hybrid model is used with the two-equation model described in equations 2 and 3. The turbulent length scale, used in this implementation, is defined as:

$$
l_{t}=\max \left(6 \sqrt{v_{t}^{R A N S} / \Omega}, k^{3 / 2} / \varepsilon\right)
$$




$$
\Omega_{j i}=\frac{1}{2}\left[\frac{\partial u_{j}}{\partial x_{i}}-\frac{\partial u_{i}}{\partial x_{j}}\right]
$$

The sub grid turbulent kinetic energy is defined as:

$$
k^{L E S}=f_{d} k
$$

The damping function is defined as:

$$
f_{d}=\{1+\tanh [2 \pi(\Lambda-0.5)]\} / 2
$$

where,

$$
\Lambda=\frac{1}{1+\left[\frac{l_{t}}{\Delta}\right]^{4 / 3}}=\frac{1}{1+\lambda^{4 / 3}}
$$

$\lambda$ is the unresolved characteristic ratio, and

$$
\Delta=\max \left(\Delta_{x}, \Delta_{y}, \Delta_{z}\right)
$$

The eddy viscosity is then calculated from:

$$
\begin{aligned}
& v_{t}=f_{d} v_{t}^{R A N S}+\left(1-f_{d}\right) v_{t}^{L E S} \\
& v_{t}^{L E S}=\min \left(v_{t}^{R A N S}, 0.084 \Delta \sqrt{k^{L E S}}\right)
\end{aligned}
$$

Note that this hybrid model allows the transition from RANS to LES as a function of the local grid spacing and the local turbulent length scale predicted by the RANS model rather than as a function of the grid spacing alone. This allows the model to detect whether it can resolve the turbulent scales present on the existing grid before its transition over to the LES mode.

\section{PAB3D History of Jet and Nozzle Simulations}

In this section, we will show results for several nozzle configurations simulated using PAB3D code. We will target the cases that show the applications of the following major additions to PAB3D:

1- Space Marching Scheme

2- Compressibility correction

3- Algebraic Reynolds Stress

4- High temperature correction

5- Multiscale Approaches (Hybrid methods)

\section{A. Supersonic Jet Flow}

This section shows examples of using Space Marching Scheme (SMS) and compressibility correction for supersonic jet flows. Figure 1 shows a sketch of the jet flow configuration for on-design axisymmetrical jets. Figure 2 shows computed centerline velocity profiles for a $M=2.22$ jet and the experimental data measured by Eggers. (65.) The solutions obtained by using different compressibility corrections are compared with experimental data. 
With no compressibility correction, the potential core length is underpredicted. The location of the end of the potential core appears to agree with the centerline velocity profile predicted using the Wilcox model. However, the potential core length of the Sarkar solution $L_{c} / R=27.15$ agrees very well with the data obtained farther downstream. The agreement between computational and measured data is much better when compressibility corrections are applied, although a small difference exists between the Sarkar model and the Wilcox solutions. Figure 3 shows the corresponding results of velocity distributions in the jet cross section at $x / R=25$. The importance of compressibility correction for supersonic jets is further illustrated here, as the compressibility-corrected computations come very close to the measured data, whereas the uncorrected computation underpredicts the centerline velocity by nearly 40 percent.

Figure 4 details computed centerline pressure distributions and experimental data for a Mach 2.0 jet at $p_{e} / p_{o}=$ 1.445 (Nozzle Pressure Ratio, NPR $=11.3$ ). Three solutions are obtained by using the basic $k-\varepsilon$ turbulence model with no compressibility correction, the Sarkar correction, and the Wilcox correction. The solution without compressibility correction shows that the amplitude of pressure oscillations diminishes rapidly downstream and the predicted wavelength is much shorter than the experimental data in the downstream region of the jet. The solutions obtained with a compressibility-corrected $k-\varepsilon$ turbulence model show general agreement with measured data. Differences between the Sarkar and Wilcox corrections are small. The amplitudes of the computed solutions closely follow the test data, but their phase relations with respect to the measured data are somewhat different. At $x / R=40$, the Wilcox solution leads the measured data by approximately one sixth of one period, whereas the Sarkar solution lags behind the measurements by approximately half that amount. All three solutions are very similar near the jet exit. However, the amplitude of the first pressure peak near the jet exit is underpredicted by approximately 15 percent.

For most jet flows where strong shocks are absent in the computational domain, the space-marching solver in the PAB3D code can be used. When the space-marching option is used for jet flow computation as conditions permit, the computer time is one-twentieth of the time required for obtaining a time-marching solution with the same flow conditions. The accuracy of the solutions obtained by these different solvers is practically indistinguishable. Substantial savings in computer time can be realized by using the space-marching method in the PAB3D code if the analyses of many cases of jet flow conditions are required for design applications.

\section{B. Fluidic Injection Nozzle}

The objective of the study was to investigate the performance of multiple injection ports in a two-dimensional, convergent-divergent nozzle for fluidic thrust vectoring through experimental and computational means. In particular, a two-dimensional, convergent-divergent nozzle with two injection ports was hypothesized to enhance the thrust vectoring ability of same nozzle with a single injection port without increasing the total secondary flow requirements or incurring significant performance penalties. In addition to verifying this hypothesis, it was the goal of the study to validate the computational fluid dynamics code, PAB3D, for multiple injection ports in a twodimensional, convergent-divergent nozzle. The validation of the computational fluid dynamics code would allow future investigations to be performed solely by computational means. The test nozzle was designed with interchangeable divergent flaps in order to investigate the effects of varying the distance between two injection ports in the upper divergent section. A total of five multi-port injection configurations were tested. The divergent flap geometry with multi-port injection and a table of important upstream injection port geometry parameters for each configuration. This case was chosen to demonstrate the ability of Algebraic Reynolds Stress model in predicting complex flow.

A computational study was conducted on two of the experimental configurations: configuration 1 and configuration 5. The configurations were run at NPRs of 4.6, 7, 8.78, and 10, all with a secondary pressure ratio, SPR of 0.7. A total of seven boundary (see Figure 5) and initial conditions were used to properly constrain and initialize the flow. The initial conditions consisted of a Mach number applied to the inflow duct of the nozzle and to the secondary flow plenum to initialize the flow. A wall "trip" point, located near the beginning of the inflow duct, was used to initialize the turbulent boundary layer of the flow. A stagnation condition was applied to the inflow duct of the nozzle and to the plenum of the secondary flow. The stagnation condition was chosen to match experimental conditions for total temperature and pressure for the inflow duct and secondary plenum. The static ambient region surrounding the nozzle was defined by various conditions. First, the left face was defined by a subsonic inflow condition. On the top and bottom faces, a characteristic boundary condition was defined. Finally, a smart boundary condition that switched between constant pressure outflow (subsonic) and first order extrapolation (supersonic), depending on the local Mach number, was applied to the right face. All solid walls were treated as no-slip adiabatic surfaces. 
Figure 6 shows the predicted flow characteristics using CFD Schlieren flow visualization for configuration 5, $\mathrm{NPR}=4.6, \mathrm{SPR}=0.7$. Qualitatively, PAB3D predicted the shock patterns very well when compared with the experimental flow patterns. Figure 7(a-d) shows the experimental and computational centerline pressures for configuration $5, \mathrm{SPR}=0.7$ ( $4 \%$ of primary mass flow rate). The PAB3D-predicted static pressures along the upper and lower nozzle surfaces correlated well with experimental data at all NPRs with a few notable exceptions in shock location, strength, and profile. The first shock location on the upper surface at all NPR's, and the shock location on the lower surface at $\mathrm{NPR}=4.6$, was predicted slightly downstream of experimental data. In particular, PAB3D predicted the first shock at $\mathrm{x} / \mathrm{x}_{\mathrm{t}}=1.3$ on the upper surface compared to a shock location of $\mathrm{x} / \mathrm{x}_{\mathrm{t}}=1.24$ in the experimental data at NPR=4.6 (Figure 7(a)). Where $x_{t}$ is the axial location of the throat. Also shown in Figure 7(a), PAB3D predicted the shock at $\mathrm{x} / \mathrm{x}_{\mathrm{t}}=1.95$ on the lower surface compared to a shock location of $\mathrm{x} / \mathrm{x}_{\mathrm{t}}=1.89$ in the experimental data. Second, PAB3D predicted a slightly stronger first shock on the upper surface compared with experimental data for all NPR, as indicated by the larger pressure rise in figure 7. On the lower surface, the start of the shock is present only at $\mathrm{NPR}=4.6$. A complete comparison of experimental and predicted pressure rise is not possible. Finally, PAB3D predicted a steeper pressure profile of the first shock on the upper surface at all NPRs, when compared to experimental data.

Results of the computational study indicate that PAB3D is useful tool for predicting the internal performance quantities of a two-dimensional, convergent-divergent nozzle with multiple injection ports. For many subsequent secondary flow injection nozzle studies, PAB3D was used with confidence in exploring different configurations for multiple injection ports.

\section{High Temperature Jet Flow}

The purpose of this study was to provide insight into the flow physics of pylon-jet interactions and to provide an input mean flow field to acoustic prediction methods for installed jet noise. The flow solution needs to be highly accurate because it is the basis for discovering important flow phenomena and it is used as input to acoustic prediction models. Four configurations were considered; a baseline round nozzle with and without a pylon, and a chevron core nozzle with and without a pylon.

The baseline configuration is a separate flow nozzle with a bypass ratio of five and with an external plug. The nozzle and pylon designs are from a nozzle study performed by Boeing in 1996 and represent a generic design. The chevrons were designed for the core nozzle using guidelines similar to those used in the NASA Advanced Subsonic Transport program. The chevrons were designed to penetrate into the core flow by approximately the thickness of the boundary layer. The four configurations analyzed in this study are:

Configuration 1: Baseline round core and fan nozzle with no pylon (Figure 8a).

Configuration 6: Baseline core and fan nozzle with pylon (Figure 8b).

Configuration 3: Eight-chevron core nozzle and baseline on nozzle with no pylon (Figure 8c).

Configuration 4F: Eight chevron core nozzle and baseline fan nozzle with pylon and with the tip of a chevron aligned with the pylon (Figure 8d)

For this study, a temperature correction turbulence model, which was tuned on the axisymmetric grid to the round nozzle experimental results, was used. Particular attention was paid to matching the axial total temperature at $x=D=5$ and 10. The model was then frozen for the other cases. Computed total temperature along the axis is plotted with experimental data in Figure 9. Comparing the data points at $x=D$ of 5 and 10 , configuration 1 is on data, configuration 3 is less than $1 \mathrm{D}$ under mixed, and configuration $4 \mathrm{~F}$ is between 1 and $2 \mathrm{D}$ under mixed. Relative errors compared to the predicted round core length are less than $11 \%$ for configuration 3 , and $11 \%$ to $22 \%$ for configuration $4 \mathrm{~F}$.

The effect of the temperature gradient modified $k-\varepsilon$ model over the standard $k-\varepsilon$ model for the round nozzle is to increase turbulent mixing and hence decrease the potential core length by 3.4 core diameters, $D$. The core lengths are defined for $\mathrm{x}=D$ in which $T_{t}=0.995 T_{t 0}$ along the axis of the jet; see Figure 9. The action of the modified $k \varepsilon$ model in terms of the increased eddy viscosity closure coefficient is shown in Figure 10, where the ratio of the actual to standard value of 0.09 is plotted. In the code, the maximum ratio is set to 5; however, its values in most of the flow fields are well below 3 . As a result of the undisturbed shear layers, which create strong temperature gradients, the round jet configuration exhibits the highest amount of $C_{\mu}$ amplification. CFD solutions of the total temperature field are depicted for the round nozzle, Figure 11, with the standard $k \varepsilon$ model followed by all configurations with the modified $k \varepsilon$ model. 


\section{Unsteady Jet Simulation}

The hybrid RANS/LES and PANS turbulence models are relatively new, and will need to be exercised for a wide variety of problems to determine their accuracy before they become an accepted tool for fluid dynamics modelers. They seem to offer much for unsteady flow applications, but issues such as grid sensitivity need to be addressed. Hopefully, more effort will go into these models in the near future, so that they can mature to a confidence level suitable for use in everyday applications. The new capabilities have the potential to improve the accuracy and robustness for unsteady flow simulation. This new class of turbulence models is inherently grid size dependent, since increasing the grid resolution allows smaller and smaller turbulent scales to be resolved. We have introduced and implemented a novel two-stage procedure to efficiently estimate the level of scale resolution possible for a given flow on a given grid, for Partial Averaged Navier-Stokes (PANS) and other hybrid models. This is a twostage procedure. In the first stage, a RANS simulation with a Standard Turbulence Model (STM) such as $k-\varepsilon$ is used to produce an estimate of $f_{\mathrm{k}}$ over the entire grid domain. In the second stage, we supply $f_{\mathrm{k}}$ for the selective application of a Hybrid Turbulence Model (HTM) such as the PANS formulation in regions where the grid density is sufficient to resolve a portion or all of the large-scale flow structures. In the present implementation, $f_{\mathrm{k}}$ is a function of length-scale and grid size that represents a characteristic length-scale ratio. We selected the subsonic high-temperature jet flows to calibrate and validate the PANS approach. This implementation is a first step towards adding a variable resolution turbulence model capability to CFD codes. The PAB3D code can now be used to refine the PANS formulation and to conduct validation computations using a variety of simple and complex flow physics problems. This approach needs to be calibrated, verified and validated for a wide range of flow problems such as different temperature jet, cavity and others.

The present study used the benchmark experiments performed by Bridges [66] at NASA Glenn Jet Flow Laboratory with the flow condition as indicated in Table 1 , for core, and free stream. In the following table, $T_{t}$ is total temperature, $P_{t}$ is the total pressure, and $M$ is the jet Mach number.

Table 1: Experimental Subsonic Condition

\begin{tabular}{|l|c|c|c|}
\hline & $T_{t}\left[{ }^{\circ}\right]$ & $P_{t}[p s i]$ & $M$ \\
\hline Core & 1400 & 17.68 & 0.55 \\
\hline Free Stream & 540 & 14.3 & 0.01 \\
\hline
\end{tabular}

The computational mesh is a full three-dimensional grid with 120 cells in the circumferential direction. The computational domain is divided into 48 blocks. The super-fine mesh has a total of 4,000,000 cells. Grid points are clustered near the solid surfaces and around the shear layer. Uniform streamwise grid spacing for $2<x / \mathrm{Dj}<12$ was used. The value of $y^{+}$for the first cell off the surface varied between 0.2 and 2. During the course of simulating this case, single and double precision calculations are used. No significant difference in the results was found. 4, 8 and 12 sub-iterations for the dual step time accurate approach were used. We also found no significant difference in the results. Based on these results, single precision and 4 sub-iterations were used in all of the presented results in this paper.

The computations used the RANS formulation to get time-averaged quantities to calculate the characteristic length-scale ratio. This ratio varies in space and is used to produce the unresolved kinetic energy parameter $\left(f_{k}\right)$. Figure 12a shows the distribution of this function. This parameter identifies the RANS and PANS regions. The RANS regions are defined with the parameter set at a value of one. The PANS regions are the remaining flow domains where $f_{k}$ values are less than one. The next stage of computation uses this parameter in the execution of the PANS formulation. Calibration of the constant $C_{h}$ used the medium grid $(1,000,000$ cells) to get the velocity profile to closely resemble the experimental data for the velocity distribution. It was determined in this process that $\mathrm{C}_{\mathrm{h}}$ should be 1.05 for the present test case. All the calculations performed hereafter used the same value of $\mathrm{C}_{\mathrm{h}}=1.05$. Figure 12b shows the two-dimensional snapshot of a slice on the X-Y plane for the velocity $\left(u / U_{j}\right)$ using the PANS formulation. The result shows the unsteady behavior of the jet flow as it interacts with the external flow. A similar observation was found for a RANS/LES formulation. In the case of RANS prediction, there was not a significant difference between the snapshot and the time-averaged flow quantities. This was caused by the fact that RANS overpredicts the eddy viscosity, resulting in excessive damping of unsteady motion. Consequently, the eddy viscosity attains un-physically large values due to unresolved scales, and suppresses most temporal and spatial fluctuations in the resolved flow field.

Figure 13 shows a comparison of the jet centerline velocity normalized to nozzle exit velocity using RANS, RANS/LES and PANS formulations as compared with experimental data. Both RANS/LES and PANS produced 
better results as when compared with RANS solution. In the case of the RANS results, the resolved kinetic energy, $k_{r}$ is zero. Both RANS/LES and PANS provided a mechanism for the RANS equations to resolve the largest scales of motion. Figure 14 shows the reduction of the unresolved kinetic energy, $k_{u}$, as compared with total value.

\section{Concluding Remarks}

The many steps of development of the PAB3D code for jet flow analysis have demonstrated that Navier-Stokes equations with properly implemented two equation $\mathrm{k}-\varepsilon$ turbulence closure models can accurately predict the mixing jet exhaust flow from simple or complex three dimension nozzles. The early PAB3D computations had duplicated the results of axisymmetric subsonic jet simulations using methods based on the mixing length hypothesis and one dimensional momentum theory that were common in the 1970's and into the early 1980's. Computations for supersonic jets had confirmed that code can also predict jet shear mixing in compressible flow when compressibility corrections were added to the turbulence model, and that the computed solutions for shock and Mach disk containing jets compared very well with classical data in the published literature. By putting jet exhaust flow computation on the basis of RANS method and published turbulence models, which are the same as those used for aerodynamic computations, it became feasible to analyze internal nozzle performance of complex three dimensional nozzles including multi-stream configurations, chevron nozzles, and internal mixers. The applications had further extended to the parametric study and design of fluidic nozzle, thrust vectoring, and propulsion airframe integration. Another important development was the application of PAB3D code to propulsion airframe aeroacoustics. In previous applications, the turbulence models were judged mainly on their ability to ensure an accurate prediction of mean flow properties and the performance coefficients of propulsion components. For aeroacoustics applications, however, the predicted turbulent kinetic energy and turbulent stresses are applied directly for noise prediction purposes. Hence, the standard of accuracy has suddenly elevated to a new level and perhaps to an unknown territory. Although early predictions using PAB3D and the JET3D code show great promises, the adequacy of the entire analytical basis for the RANS approach and various turbulence model formulations are again open to questions and intense scrutiny. In this process, a temperature correction to the turbulence model was implemented and tested for hot jet applications, and a broad range of hybrid Navier Stokes computations methods were examined for their relevance to modeling the fundamental unsteadiness of jet flow and their application to jet aeroacoustics predictions. It is fair to say at this point that many years of interesting and fruitful research in the area are still ahead in the future.

\section{References}

1. Reichardt, Hans: Gesetzmässigkeiten der freien Turbulenz. VDI-Forschungsh. 414, 1942.

2. Görtler, H. "Berechnung von Aufgaben der freien Turbulenz auf Grund eines neuen Näherungsansatzes. $Z$. Angew. Math. Mech,” Bd. 22, Nr. 5, Oct. 1942, pp. 244-254.

3. Warren, Walter R., Jr. "An Analytical and Experimental Study of Compressible Free Jets." Publ. No.: 23,885, Univ. Microfilms, Inc., 1957.

4. Abramovich, G. N.: The Theory of Turbulent Jets. M.I.T. Press, 1963.

5. Love, Eugene S. Grigsby, Carl E., Lee, Louise P., and Woodling, Mildred J. "Experimental and Theoretical Studies of Axisymmetric Free Jets," NASA TR R-6, 1959. (Supersedes NACA RM L54L31 by Love and Grigsby, RM L55J14 byLove, RM L56G18 by Love, Woodling, and Lee, and TN 4195 by Love and Lee.)

6. Dash, Sanford M., and Wolf, David E. "Fully-Coupled Analysis of Jet Mixing Problems, Part I," ShockCapturing Model, SCIPVIS. NASA CR-3716, 1984.

7. Dash, Sanford M., Pergament, Harold S., and Thorpe, Roger D. "Computational Models for the Viscous/Inviscid Analysis of Jet Aircraft Exhaust Plumes," NASA CR-3289, 1980.

8. Seiner, John M. “Advances in High Speed Jet Aeroacoustics," AIAA-84-2275, Oct. 1984.

9. Seiner, J. M., and Norum, T. D. "Aerodynamic Aspects of Shock Containing Jet Plumes," AIAA-80-0965, June 1980.

10. Abdol-Hamid, Khaled S., and Wilmoth, Richard G. "Multiscale Turbulence Effects in Underexpanded Supersonic Jets," AIAA J., vol. 27, Mar. 1989, pp. 315-322.

11. Abdol-Hamid, Khaled S. "The Application of 3D Marching Scheme for the Prediction of Supersonic Free Jets," AIAA/ASME/SAE/ and ASEE 25th Joint Propulsion Conference, July 1989. (Available as AIAA-892897.)

12. Abdol-Hamid, Khaled S., Uenishi, Kenji, and Turner, William "Three-Dimensional Upwinding Navier-Stokes 
Code With $k-\varepsilon$ Model for Supersonic Flows,” AIAA-91-1669, June 1991.

13. Seiner, J.M., Ponton, M.K., Jansen, B. J., and Lagen, N. T., "The Effects of Temperature on Supersonic Jet Noise Emission," DGLR/AIAA 14th Aeroacoustics Conference, Aachen, Germany, AIAA Paper No. 92-02046, May 1992.

14. Thomas, R.H., Kinzie, K.W. and Pao, S. Paul, "Computational Analysis of a Pylon-Chevron Core Nozzle Interaction," AIAA Paper 2001-2185, May 2001.

15. Theis, A. T., and Tam, C. K. W., "Computation of Turbulent Axisymmetric and Non-axisymmetric Jet Flows Using the k-e Model," AIAA Journal, Vol. 34, No. 2, February 1996, pp. 309-316.

16. Tam, C. K.W., and Ganesan, A., "A Modified k- $\varepsilon$ Model for Calculating the Mean Flow and Noise of Hot Jets," AIAA 2003-1064, January 2003.

17. Lebedev A. B., Lyubimov A. D., Maslov, V. P., Mineev, B. I., Secundov, A. N., and Birch, Stanley F., "The Prediction of Three-Dimensional Jet Flows for Noise Applications," AIAA 2002-2422, 2002.

18. So, R.M.C., and Sommer, T. P., "An Explicit Algebraic Heat-Flux Model for the Temperature Field," International Journal of Heat and Flow, 1995, Vol. 7, pp. 455-465.

19. Ronki, M., and Gatski, Thomas B., "Predicting Turbulent Convective Heat Transfer in Fully Developed Duct Flows," International Journal of Heat and Flow, Vol. 22, 2001, pp. 381-392.

20. Abe, K., Kondoh, T., and Nagano, Y., "A Two-equation Heat Transfer Model Reflecting Second-Moment Closures for Wall and Free Turbulent Flows," International Journal of Heat and Flow, Vol. 17, 1996, pp. 228237.

21. Abdol-Hamid, K. S., Pao, S, Massey, S. J., and Elmiligui, A., "Temperature Corrected Turbulence Model for High Temperature Jet Flow.” ASME Journal of Fluids Engineering, Vol. 126, No 5, September 2004.

22. Jones, W. P., and Launder, B. E. "The Prediction of Laminarization With a Two-Equation Model of Turbulence," Int. J. Heat \& Mass Transf., vol. 15, no. 2, Feb. 1972, pp. 301-314.

23. Spalart, P. R., "Young Person's Guide to Detached Eddy Simulation Grids," NASA CR-2001, 211032, 2001.

24. Nichols, R.H. \& Nelson, C.C., "Application of Hybrid RANS/LES Turbulence Models" AIAA 2003-0083, 2003.

25. Mani, M., Paynter, C.C., "Hybrid Turbulence Models for Unsteady Simulation of Jet Flows." AIAA 20022959, 2002.

26. Batten, P., Goldberg, U., and Chakravarthy, S., "LNS - An Approach Towards Embedded LES," AIAA Paper 2002-0427, 2002.

27. Girimaji S., Sreenivasan, R., Jeong E., "PANS Turbulence Model For Seamless Transition Between RANS, LES: Fixed-Point Analysis and Preliminary Results." FEDSM2003-45336, Proceedings of ASME FEDSM'03 2003 4th ASME-JSME Joint Fluids Engineering Conferences, July 13-16, Honolulu, Hawaii USA, 2003.

28. Abdol-Hamid, K., and Girimaji, S. "A Two-Stage Procedure Toward the Efficient Implementation of PANS and Other Hybrid Turbulence Models," NASA TM-213260, 2004.

29. Abdol-Hamid, K.S. "Development of Three-Dimensional Code for the Analysis of Jet Mixing Problem," NASA CR 4200, December 1988.

30. Abdol-Hamid, K.S.: A Multiblock/Multizone code (PAB3D-v2) for the Three-Dimensional Navier-Stokes Equations: Preliminary Applications, NASA CR-182032, 1990.

31. Uenishi, K. and Abdol-Hamid, K.: A Three-Dimensional Upwinding Navier-Stokes Code with k- $\varepsilon$ Model for Supersonic Flows", AIAA 22nd Fluid and Plasmadynamic Conference, AIAA 91-1669, June 1991.

32. Abdol-Hamid, K. S.; Lakshmanan, B.; and Carlson, J. R.: Application of Navier-Stokes Code PAB3D with k$\varepsilon$ Turbulence Model to Attached and Separated Flows. NASA TP-3480, January 1995

33. Abdol-Hamid, K. S.: Implementation of Algebraic Stress Models in a General 3-D Navier-Stokes Method (PAB3D). NASA CR-4702, December 1995.

34. Carlson, J. R., "Applications of Algebraic Reynolds Stress Turbulence Models," Journal of Propulsion and Power, Volume 13, Number 5, 1997.

35. Shih, T.H., Zhu, J., and Lumley, J.L., "A New Reynolds Stress Algebraic Equation Model," NASA TM106644, August 1994.

36. Girimaji, S.S., "Fully-Explicit and Self-Consistent Algebraic Reynolds Stress Model," ICASE 95-82, December 1995.

37. Nichols, R.H. \& Nelson, C.C., "Application of Hybrid RANS/LES Turbulence Models" AIAA 2003-0083, 2003.

38. Abdol-Hamid, K.S. "Three-Dimensional Calculations for Underexpanded and Over expanded Supersonic Jet Flows," AIAA Paper 89-2196, September 1989.

39. Lakshmanan, B. and Abdol-Hamid, K. S. "Application of Space Marching Procedure for Transport Equation of 
Turbulence Models.” Computational Fluid Dynamics Journal, Vol. 1. No. 3, October 1992.

40. Lakshmanan, B., and Abdol-Hamid, K. S. "Investigation of Supersonic Jet Plumes Using an Improved TwoEquation Turbulence Model." Journal of Propulsion and Power, Volume 10, Number 5, September-October 1994, pp. 736-741.

41. Pao, S. P., and Abdol-Hamid, K. S. "Grid Adaptation to Multiple Functions for Applied Aerodynamic Analysis," Proceedings of the Third International Conference on Numerical Grid Generation, Barcelona, Spain, June 1991.

42. Abdol-Hamid, K. S., Uenishi, K., Keith, B. D., and Carlson, John R. "Commercial Turbofan Engine Exhaust Nozzle Flow Analyses,” Journal of Propulsion and Power, Vol. 9, No. 3, May-June 1993.

43. Jones, W.T. and Abdol-Hamid K.S. "Computational Analysis of Drag Reduction Techniques for Afterbody/Nozzle/Empennage Configurations. Aerospace Technology Conference and Exposition," Long Beach, California September 1992.

44. Carlson, J. R., Pao, S. P., Abdol-Hamid, K. S., and Jones, W. T. "Aerodynamic Performance Predictions of Single and Twin Jet Afterbodies," AIAA 95-2622, 31st AIAA/ASME/SAE/ASEE Joint Propulsion Conference and Exhibit, San Diego, CA, July 10-12, 1995.

45. Carlson, John R., Abdol-Hamid, K.S., and Pao, S. Paul "Computational Analysis of Vented Supersonic Exhaust Nozzle Using a Multiblock/Multizone Strategy" Journal of Propulsion and Power, Vol. 9, No. 6, November-December 1993.

46. Pao, S. P., Carlson, J. R., and Abdol-Hamid, K. S. "Computational Investigation of Circular-to-Rectangular Transition Ducts," Journal of Propulsion and Power, Volume 10, Number 1, January-February 1994, pp. 95100 .

47. Carlson, J. R., and Asbury, S. C. "Two-Dimensional Converging-Diverging Rippled Nozzles at Transonic Speeds," NASA TP-3440, July 1994.

48. Kuhne, C. M., Uenishi, K., Leon, R. M., Abdol-Hamid, K. S. "CFD Based 3D Aero Analysis System for HighSpeed Mixer-Ejector Exhaust Nozzles," AIAA 94-2941, 30th AIAA/ASME/SAE/ASEE Joint Propulsion Conference, Indianapolis, IN, June 27-29, 1994.

49. Walter M. Presz, Jr., Gary Reynolds and Craig Hunter "Thrust Augmentation With Mixer/Ejector Systems," 40th AIAA Aerospace Sciences Meeting and Exhibit, Reno, Nevada, AIAA 2002-0230, January 14-17, 2002.

50. Carlson, John R., and Abdol-Hamid, Khaled S. "Prediction of Static Performance for Single Expansion Ramp Nozzles," AIAA Paper No. 93-2571, AIAA/SAE/ ASME/ASEE 29th Joint Propulsion Conference, June 28-30, 1993.

51. Deere, K. A., and Asbury, S. C. "An Experimental and Computational Investigation of a Translating Throat Single Expansion-Ramp Nozzle." AIAA 96-2540, 32nd AIAA/ASME/SAE/ASEE Joint Propulsion Conference \& Exhibit, Lake Buena Vista, FL, July 1-3, 1996.

52. Deere, K. A. and Asbury, S. C. "Experimental and Computational Investigation of a Translating-Throat, Single-Expansion-Ramp Nozzle," NASA TP-1999-209138, May 1999.

53. Deere, K. A. "PAB3D Simulations of a Nozzle With Fluidic Injection for Yaw Thrust-Vector Control," 34th AIAA/ASME/SAE/ASEE Joint Propulsion Conference and Exhibit, Cleveland, Ohio, AIAA 98-3254, July 1315, 1998, pp. 12.

54. Hunter, Craig A. and Deere, Karen A. "Computational Investigation of Fluidic Counterflow Thrust Vectoring," AIAA 99-2669, presented at the 35th Annual AIAA/ASME/SAE/ASEE Joint Propulsion Conference, Los Angeles, CA, June 20-23, 1999.

55. Deere, K.A., Berrier, B.L., Flamm, J. D., and Johnson, S. K. "Computational Study of Fluidic Thrust Vectoring Using Separation Control in a Nozzle," $21^{\text {st }}$ AIAA Applied Aerodynamics Conference, Orlando, FL. AIAA 2003-3800, June 23-26, 2003

56. Deere, K.A. "Summary of Fluidic Thrust Vectoring Research at NASA Langley Research Center." $21^{\text {st }}$ AIAA Applied Aerodynamics Conference, Orlando, FL. AIAA 2003-3800, June 23-26, 2003.

57. Deere, K.A., Berrier, B.L., Flamm, J.D., and Johnson, S.K. "A Computational Study of a New Dual Throat Fluidic Thrust Vectoring Nozzle Concept." $41^{\text {st }}$ AIAA/ASME/SAE/ASEE Joint Propulsion Conference and Exhibit, Tucson, AZ. AIAA 2005-3502, July 11-13, 2005.

58. Thomas, R. H., Kinzie, K. W., and Pao, S. P. "Computational Analysis of a Paylon-Cheveron Core Nozzle Interaction," 7th AIAA/CEAS Aeroacoustics Conference, Maastricht, The Netherlands, AIAA 2001-2185, May 28-30, 2001

59. Hunter, C., Pao, S. and Thomas, R. "Development of a Jet Noise Prediction Method for Installed Jet Configurations," 9th AIAA/CEAS Aeroacoustics Conference and Exhibit, May 12-14, 2003, Hilton Head, South Carolina. AIAA 2003-3169. 
60. Massey, S.J., Thomas, R.H., Abdol-Hamid, K. S., and Elmiligui, A. "Computational and Experimental Flowfield Analyses of Separate Flow Chevron Nozzles and Pylon Interaction," 9th AIAA/CEAS Aeroacoustics Conference and Exhibit, May 12-14, 2003, Hilton Head, South Carolina. AIAA-2003-3212.

61. Abdol-Hamid, K.S., Pao, S, Massey, S.J., and Elmiligui, A., "Temperature Corrected Turbulence Model for High Temperature Jet Flow." ASME Journal of Fluids Engineering, Vol. 126, No 5, September 2004.

62. Pao, S. Paul and Abdol-Hamid, K. S. "Numerical Simulation of Jet Aerodynamics Using Three-dimensional Navier-Stokes Method (PAB3D)," NASA TP-3596, September 1996.

63. Abdol-Hamid, K., and Elmiligui, A., "Numerical Study of High Temperature Jet Flow Using RANS/LES and PANS Formulation," AIAA Paper 2005-5092, Toronto, 2005.

64. Elmiligui, A., Abdol-Hamid, K., and Hunter, C. "Numerical Investigation Flow in an Over-Expanded Nozzle with Porous Surfaces", AIAA Paper 2005-4159, Tucson, Arizona, 2005.

65. Eggers, James M.: Velocity Profiles and Eddy Viscosity Distributions Downstream of a Mach 2.22 Nozzle Exhausting to Quiescent Air. NASA TN D-3601, 1966.

66. Bridges, J. and Brown, C., "Parametic Testing on Single Flow Hot Jet," AIAA 2004-2824, 2004. 


\section{Appendix Algebraic Stress Models Equation Parameters}

The following functions and variables were used in the algebraic Reynolds stress models used by the SZL model:

$$
\begin{aligned}
& C_{\mu}^{*}=\frac{1}{\left(6.5+A_{s}^{*} \frac{U^{*} k}{\varepsilon}\right)} \\
& C_{\mu}^{*}=\frac{1}{\left(6.5+A_{s}^{*} \frac{U^{*} k}{\varepsilon}\right)} \\
& A_{s}^{*}=\sqrt{6} \cos (\phi) \\
& S=\sqrt{S_{i j} S_{i j}} \\
& S^{*}=S_{i j} S_{j k} S_{k i} /(S)^{3} \\
& U^{*}=\sqrt{S_{i j} S_{i j}+W_{i j} W_{i j}} \\
& \phi=\frac{1}{3} \cos ^{-1}\left(\sqrt{6} S^{*}\right) \\
& W=\sqrt{W_{i j} W_{i j}} \\
& \beta=\frac{\sqrt{1-9 C_{\mu}^{2}\left(\frac{S k}{\varepsilon}\right)^{2}}}{\left(1+6 \frac{S k}{\varepsilon} \frac{W k}{\varepsilon}\right)}
\end{aligned}
$$

The following functions and variables were used in the algebraic Reynolds stress models used by Girimaji model:

$$
\begin{gathered}
L_{1}^{0}=\frac{C_{1}^{0}}{2}-1 \quad L_{1}^{1}=C_{1}^{1}+2 \\
L_{2}=\frac{C_{2}}{2}-\frac{2}{3} \quad L_{3}=\frac{C_{3}}{2}-1 \quad L_{4}=\frac{C_{4}}{2}-1 \\
\eta_{1}=\left(\frac{k}{\varepsilon}\right)^{2} \bar{S}_{m n} \bar{S}_{m n} \quad p=-\frac{2 L_{1}^{0}}{\eta_{1} L_{1}^{1}} \\
q=\frac{1}{\left(\eta_{1} L_{1}^{1}\right)^{2}}\left[\left(L_{1}^{0}\right)^{2}+\eta_{1} L_{1}^{1} L_{2}-\frac{2}{3} \eta_{1}\left(L_{3}\right)^{2}+2 \eta_{2}\left(L_{4}\right)^{2}\right] \\
\left.q=\frac{p^{2}}{3}\right)^{2} W_{m n} W_{m n} \quad \quad b=\frac{1}{27}\left(2 p^{3}-9 p q+27 r\right) \\
D=\frac{b^{2}}{4}+\frac{\left.a^{3} L_{1}^{1}\right)^{2}}{27} \quad \cos (\theta)=\frac{-b / 2}{\sqrt{-a^{3} / 27}}
\end{gathered}
$$

The coefficients $\mathrm{G}_{2}$ and $\mathrm{G}_{3}$ are

$$
G_{2}=\frac{-L_{4} G_{1}}{L_{0}^{1}-\eta_{1} L_{1}^{1} G_{1}} \quad G_{3}=\frac{-L_{3} G_{1}}{L_{0}^{1}-\eta_{1} L_{1}^{1} G_{1}}
$$




$$
G_{1}= \begin{cases}L_{0}^{1} L_{2} /\left[\left(L_{1}^{0}\right)^{2}+2 \eta_{2}\left(L_{4}\right)^{2}\right] & \text { for } \eta_{1}=0 \\ -\frac{p}{3}+\left(-\frac{b}{2}+\sqrt{D}\right)^{1 / 3}+\left(-\frac{b}{2}-\sqrt{D}\right)^{1 / 3} & \text { for } D>0 \\ -\frac{p}{3}+2 \sqrt{\frac{-a}{3}} \cos \left(\frac{\theta}{3}\right) & \text { for } D<0 \quad \text { and } b<0 \\ -\frac{p}{3}+2 \sqrt{\frac{-a}{3}} \cos \left(\frac{\theta}{3}+\frac{2 \pi}{3}\right) & \text { for } D<0 \quad \text { and } b>0 \\ C_{1}^{0}=3.4 \quad C_{1}^{1}=1.8 \quad C_{2}=0.36 \quad C_{3}=1.25 \quad C_{4}=0.4\end{cases}
$$




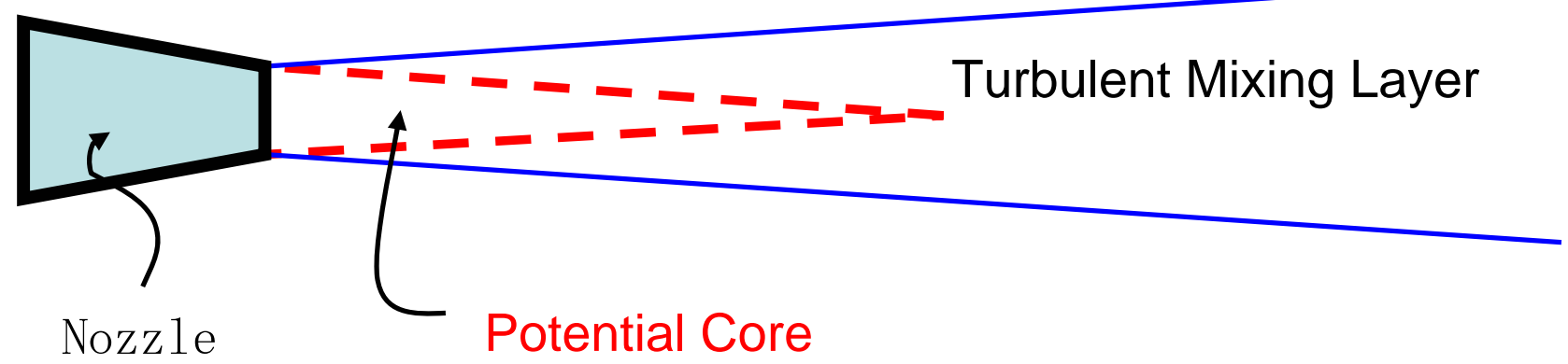

Figure 1.Typical on-design jet flow configuration and terminology.

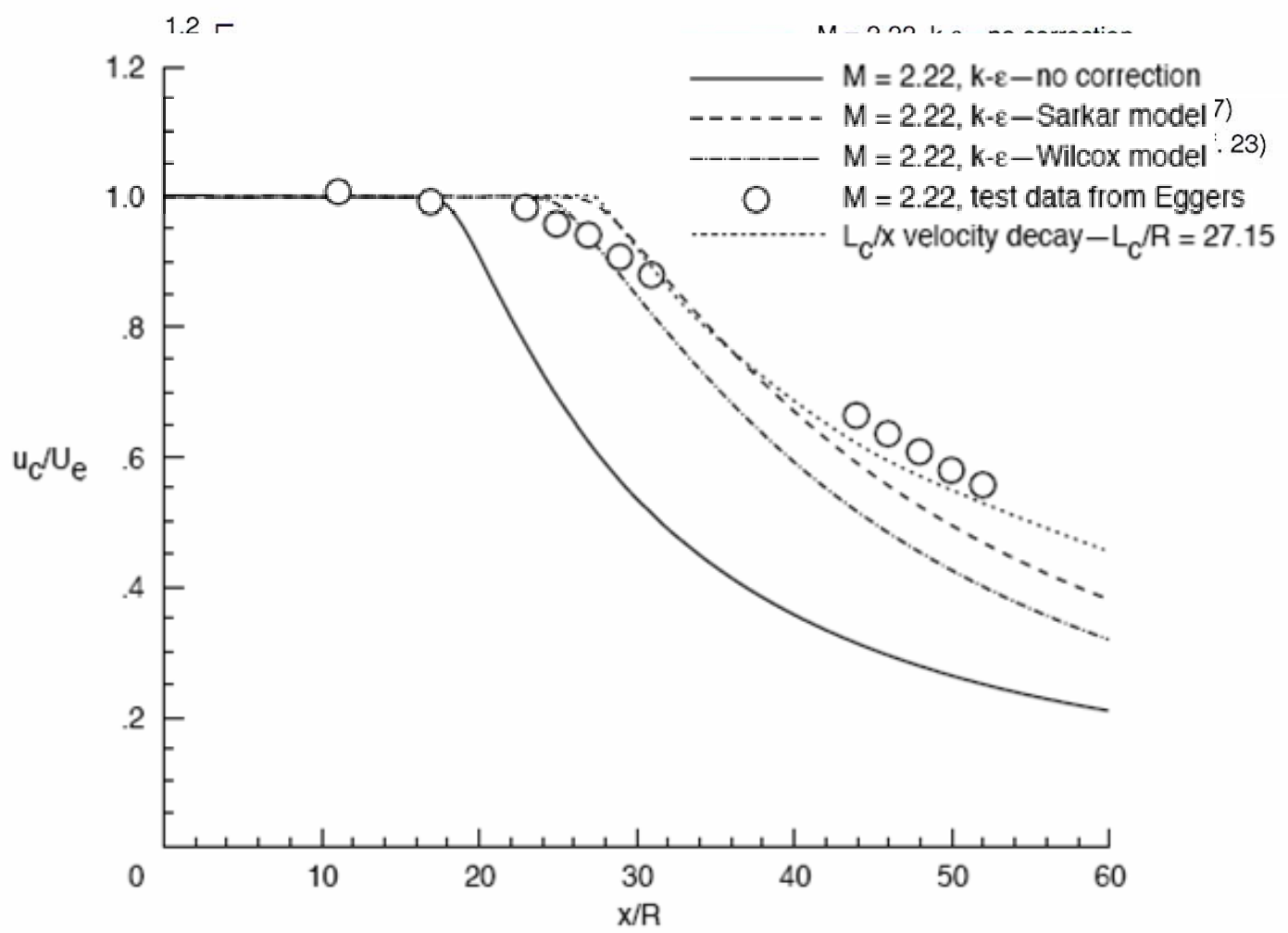

Figure 2. Centerline velocity distribution for supersonic jet using $k-\varepsilon$ turbulence model with different compressibility corrections. 


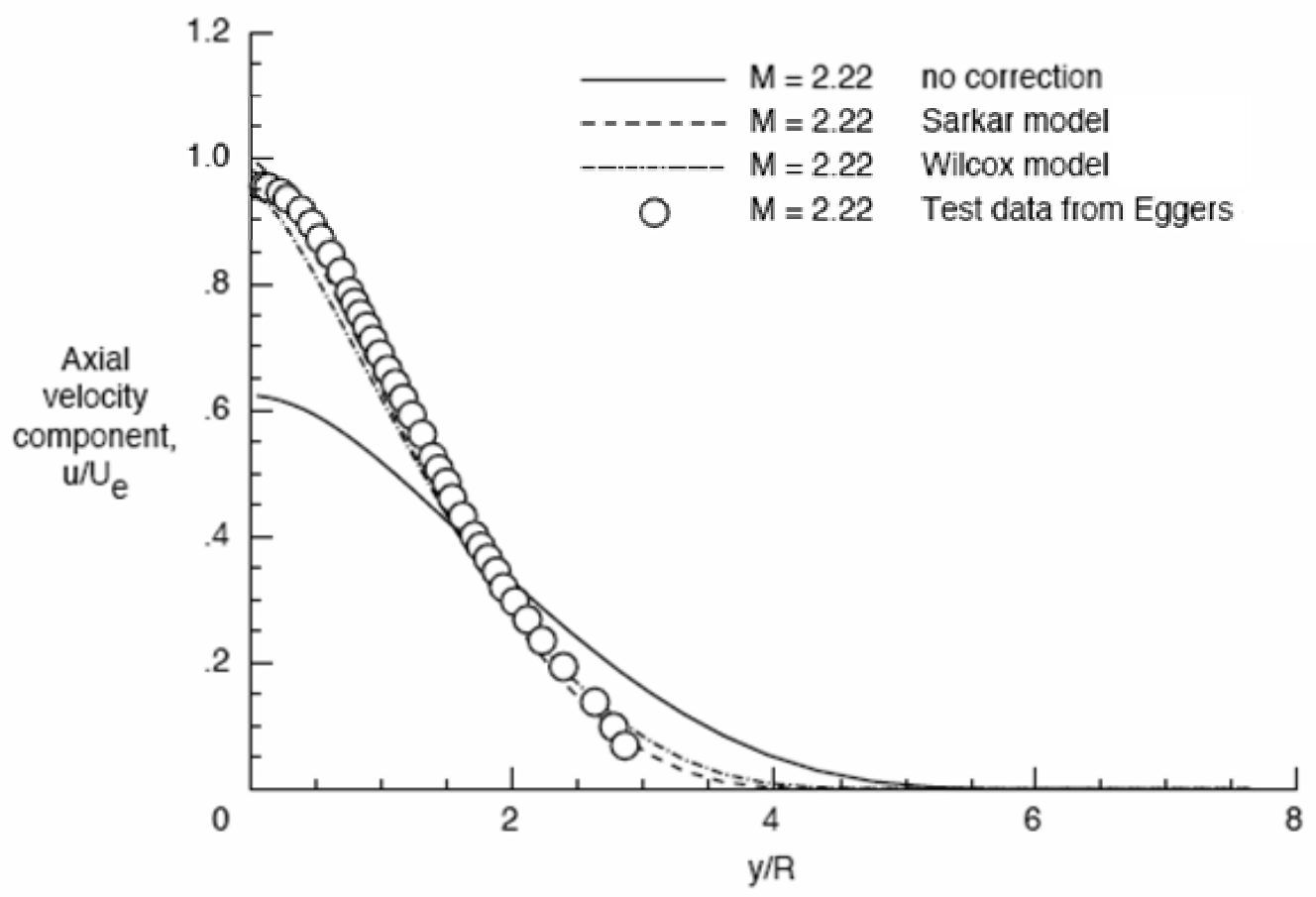

Figure 3. Axial velocity component distribution along radial direction at $x / R=25$ using $k-\varepsilon$ turbulence model with different compressibility corrections.

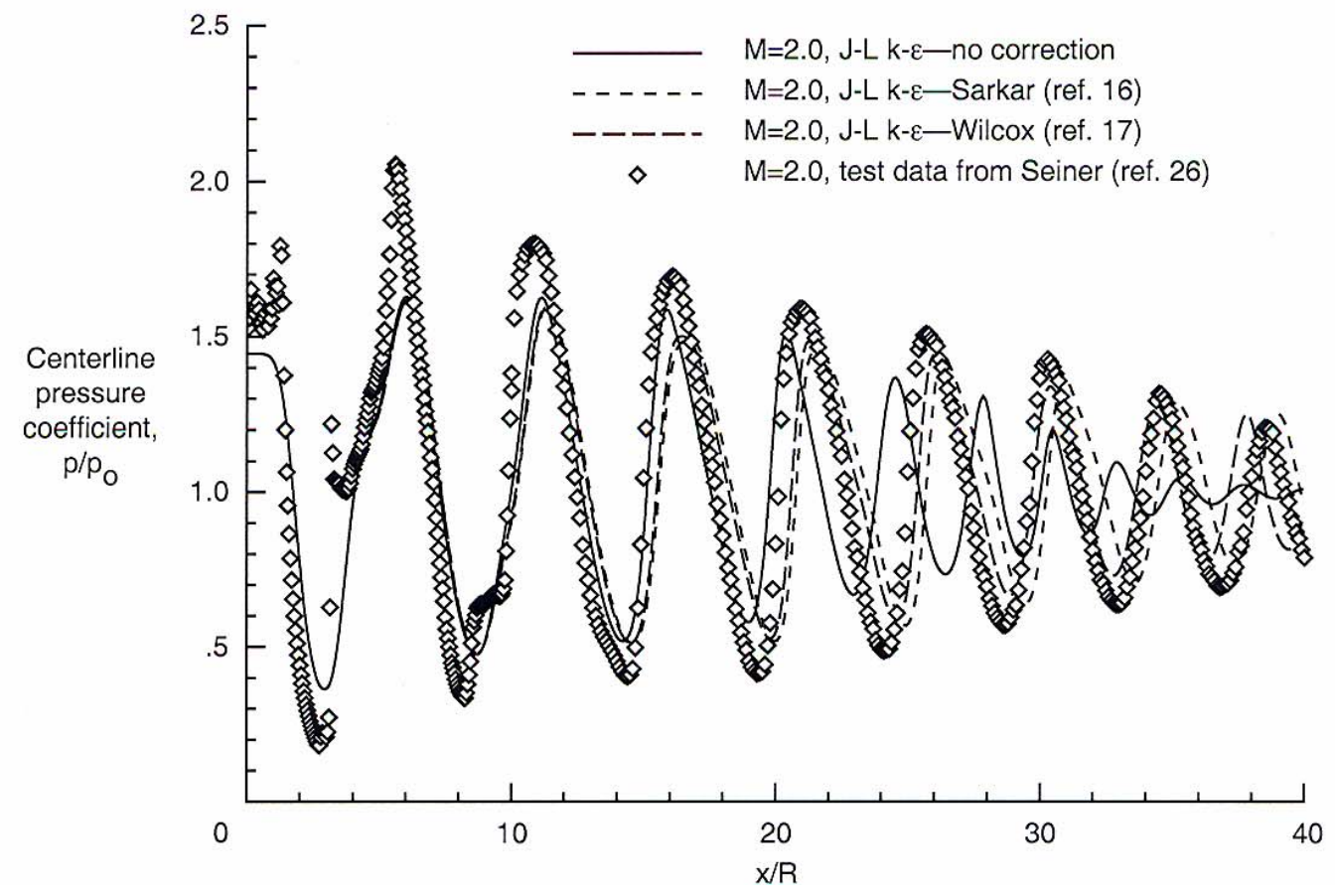

Figure 4. Centerline pressure distribution computed with Jones-Launder $k-\varepsilon$ model with different compressibility corrections for $p e / p o=1.445$. 


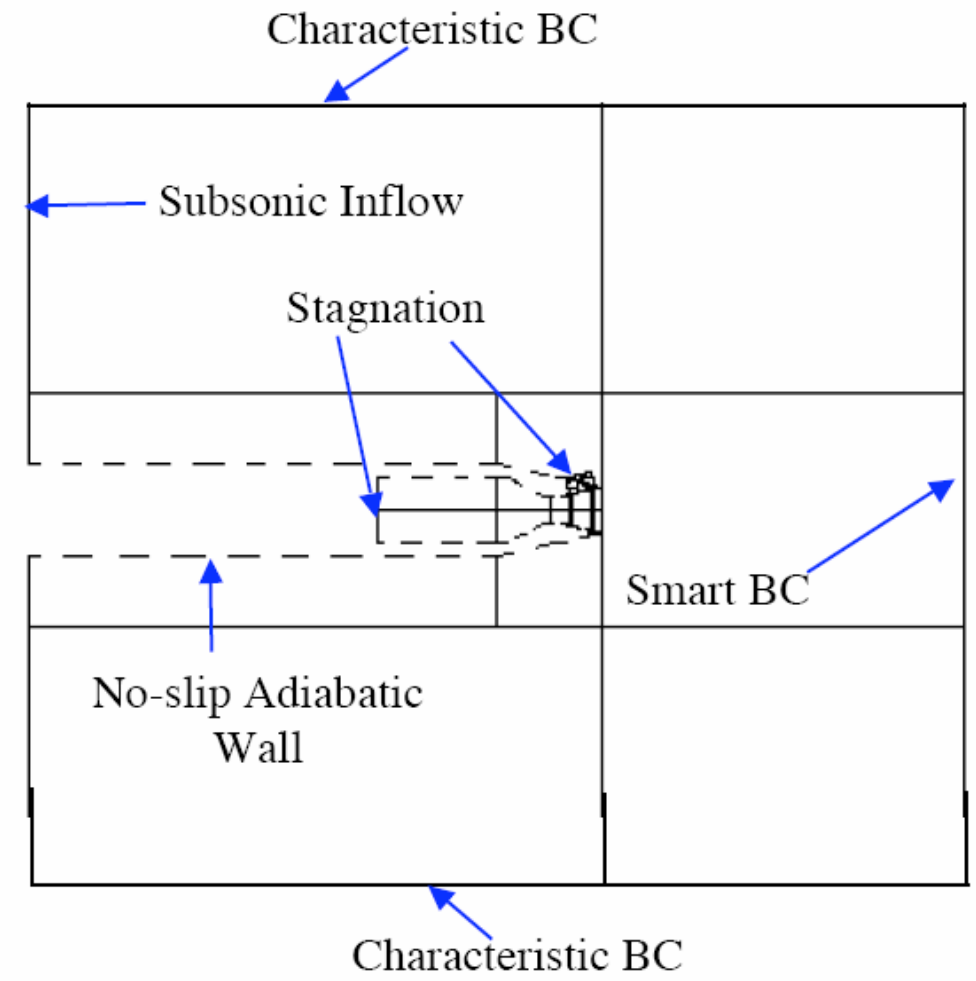

Figure 5. Boundary Conditions.

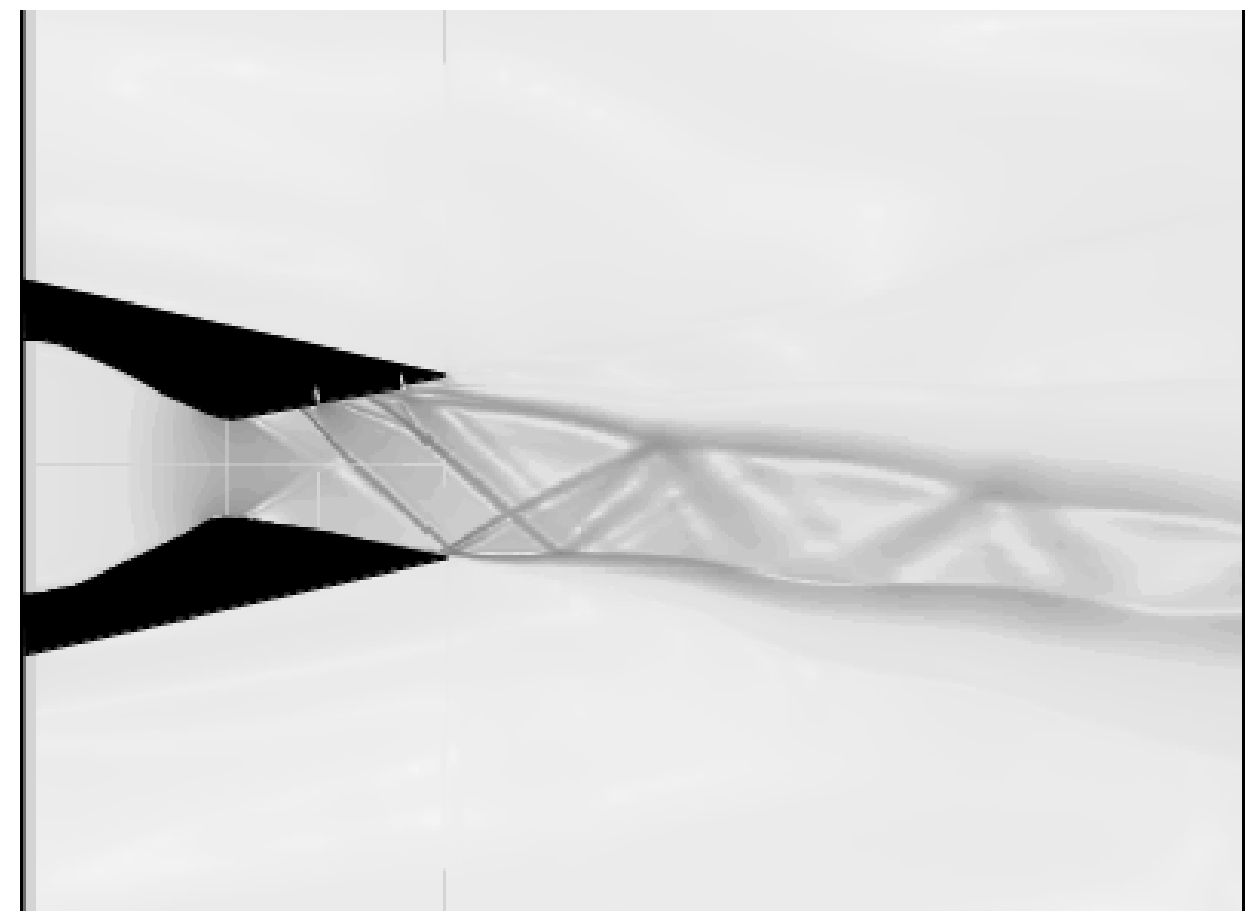

Figure 6. CFD Schlieren for configuration 5, $\mathrm{NPR}=4.6, \mathrm{SPR}=0.7$. 


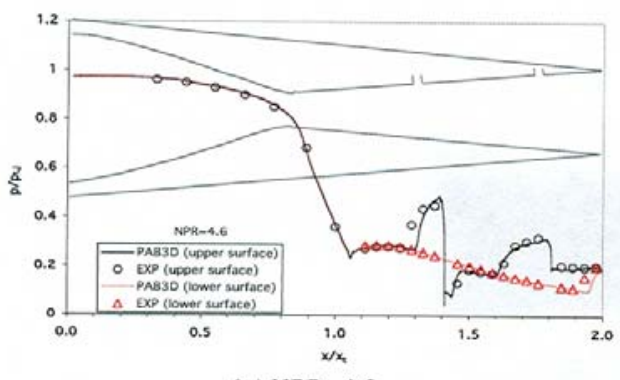

(a) $N P R=4.6$.

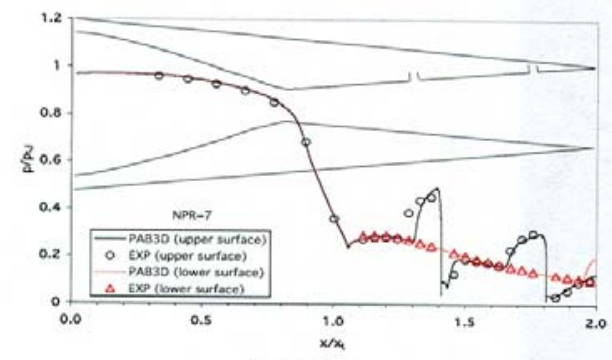

(b) $N P R=7$.

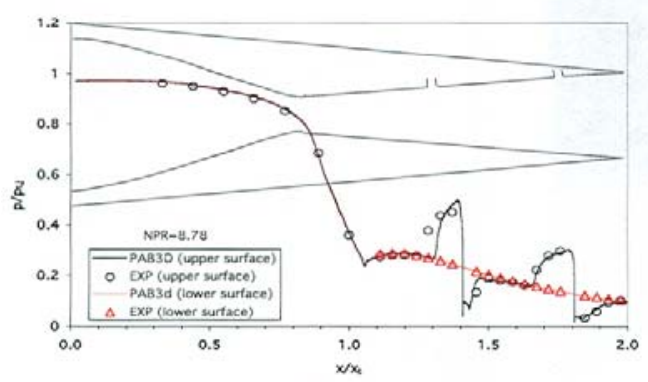

(c) $N P R=8.78$.

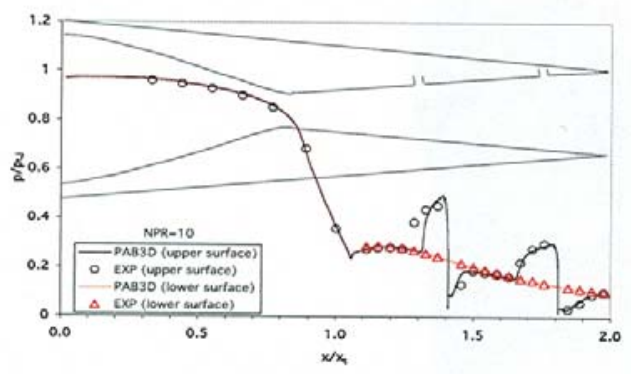

(d) $N P R=10$.

Figure 7. Experimental and computational centerline pressures for configuration $5, S P R=0.7$.

American Institute of Aeronautics and Astronautics 


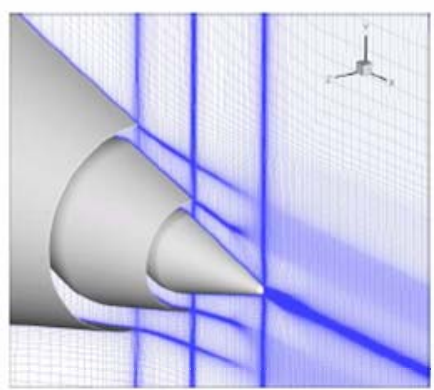

a) Config. 1

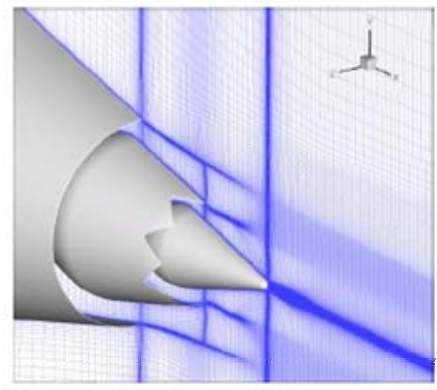

c) Config. 3

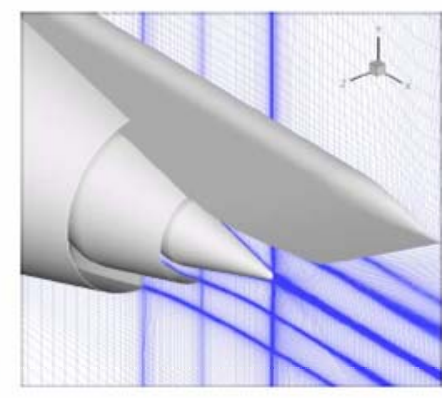

b) Config. 6

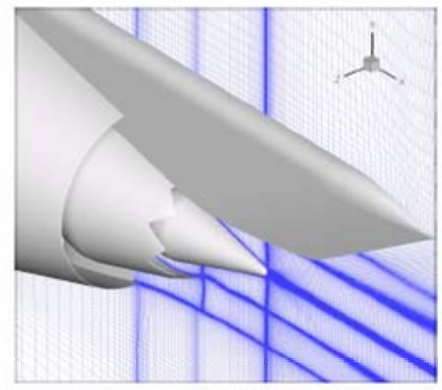

d) Config. $4 \mathrm{~F}$

Figure 8 . Surface and symmetry plane grid lines.

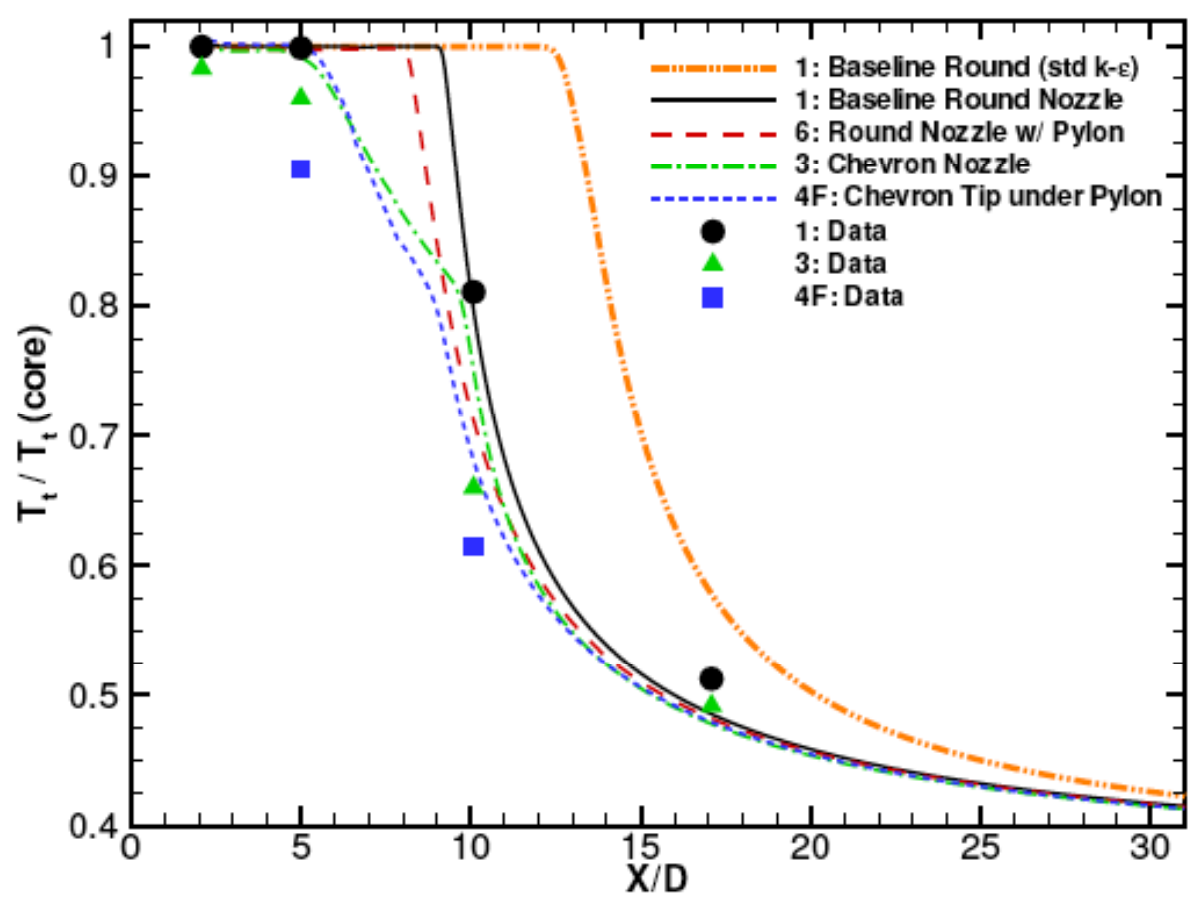

Figure 9. Total temperature along jet axis. 

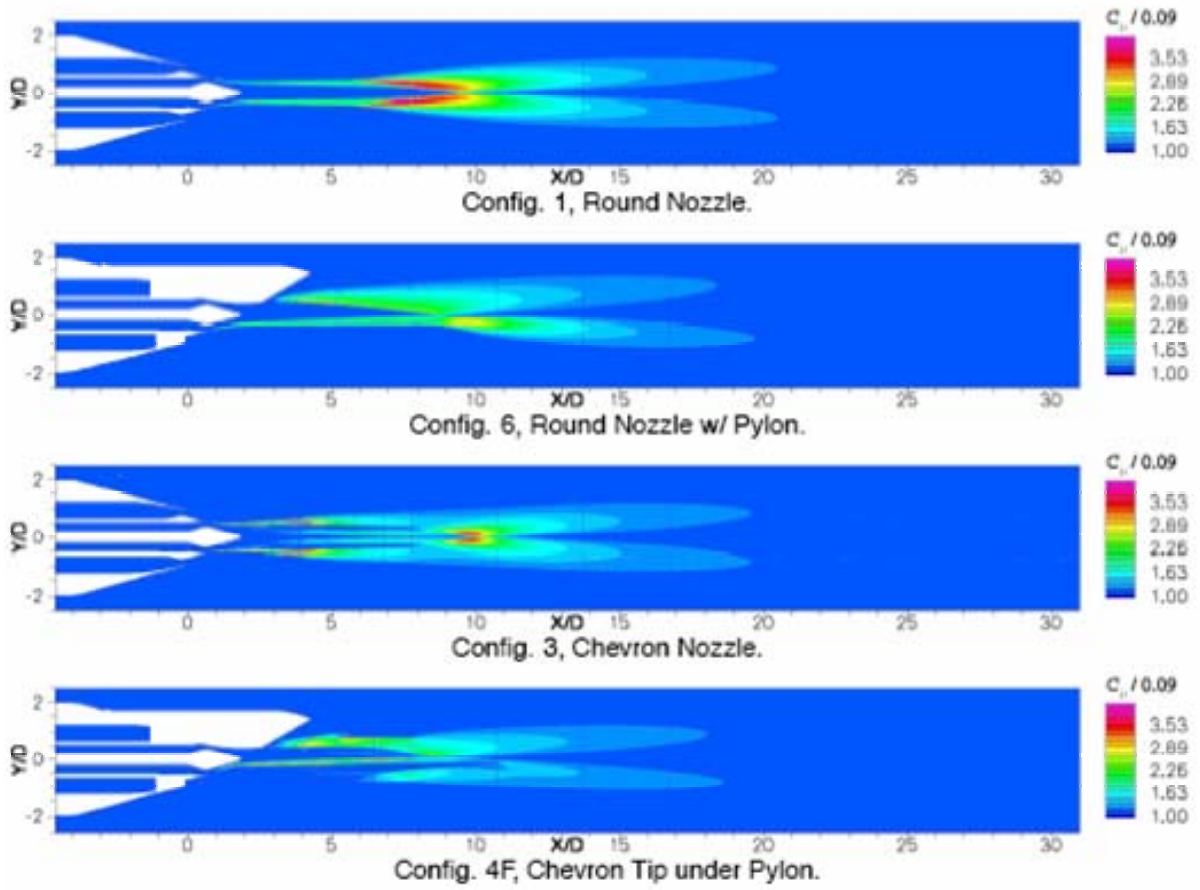

Figure 10. CFD: $C \mu$ factor on symmetry plane.
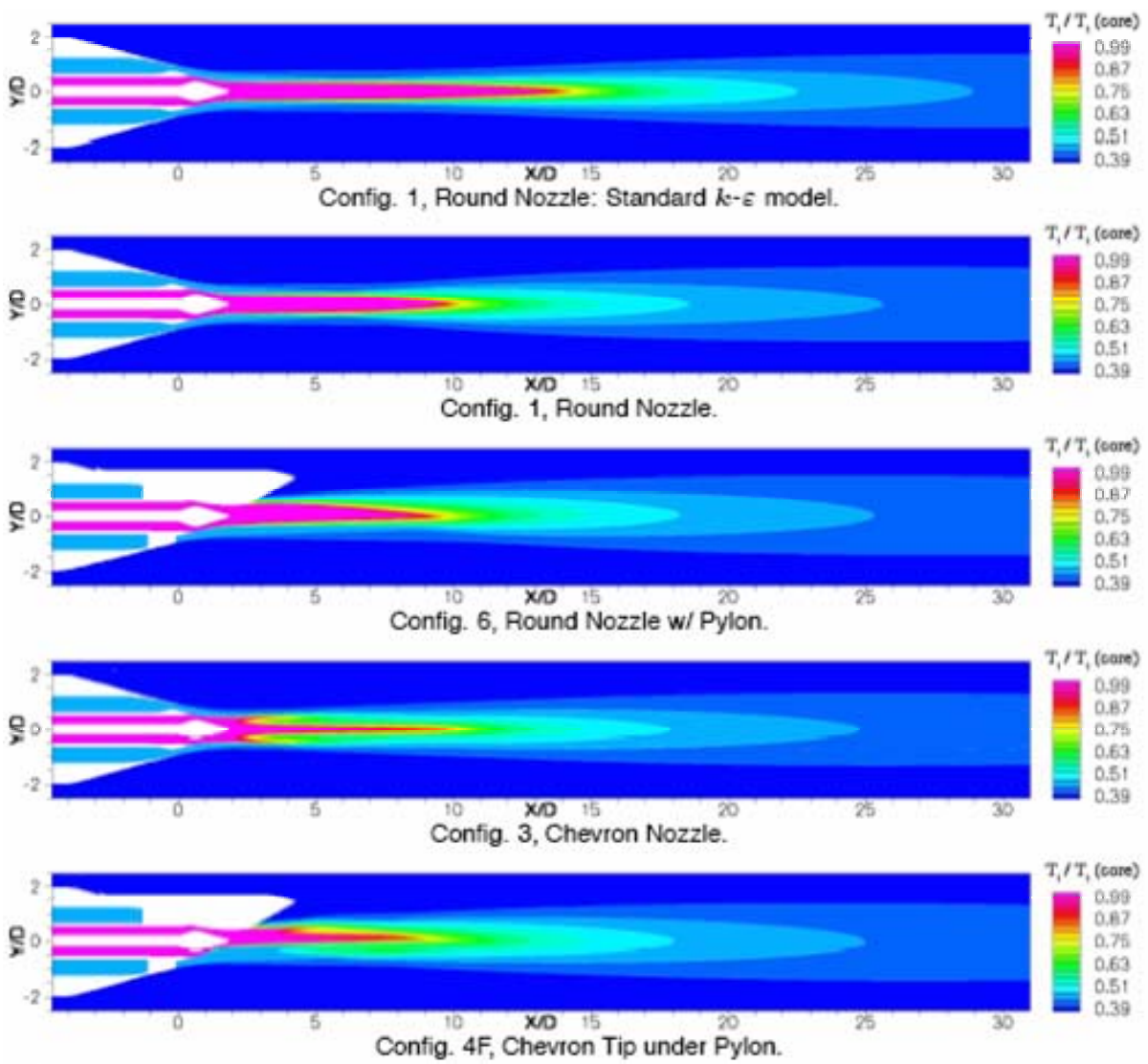

Figure 11. CFD: Total temperature on symmetry plane. 


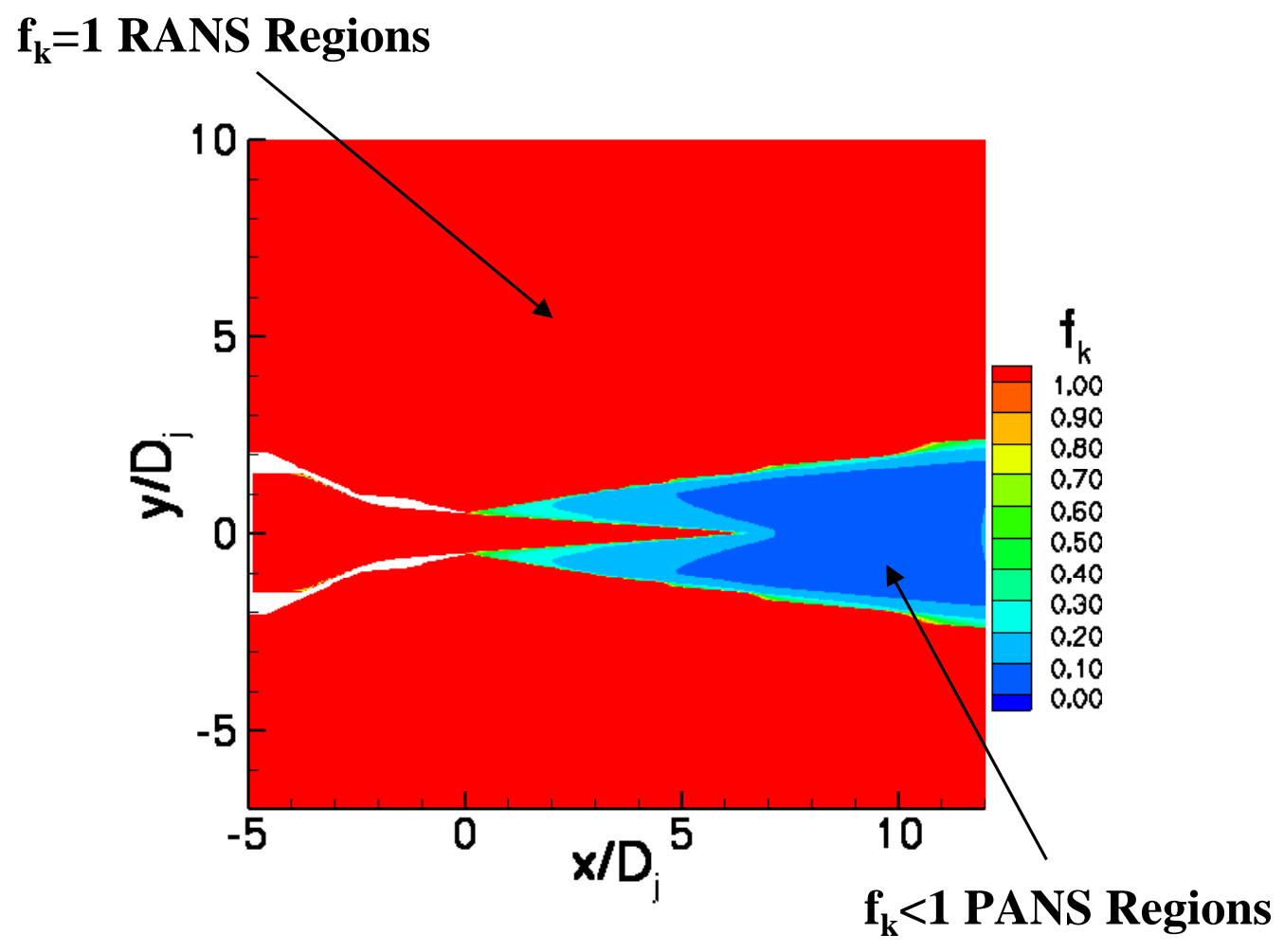

a) Unresolved Turbulent Kinetic Energy

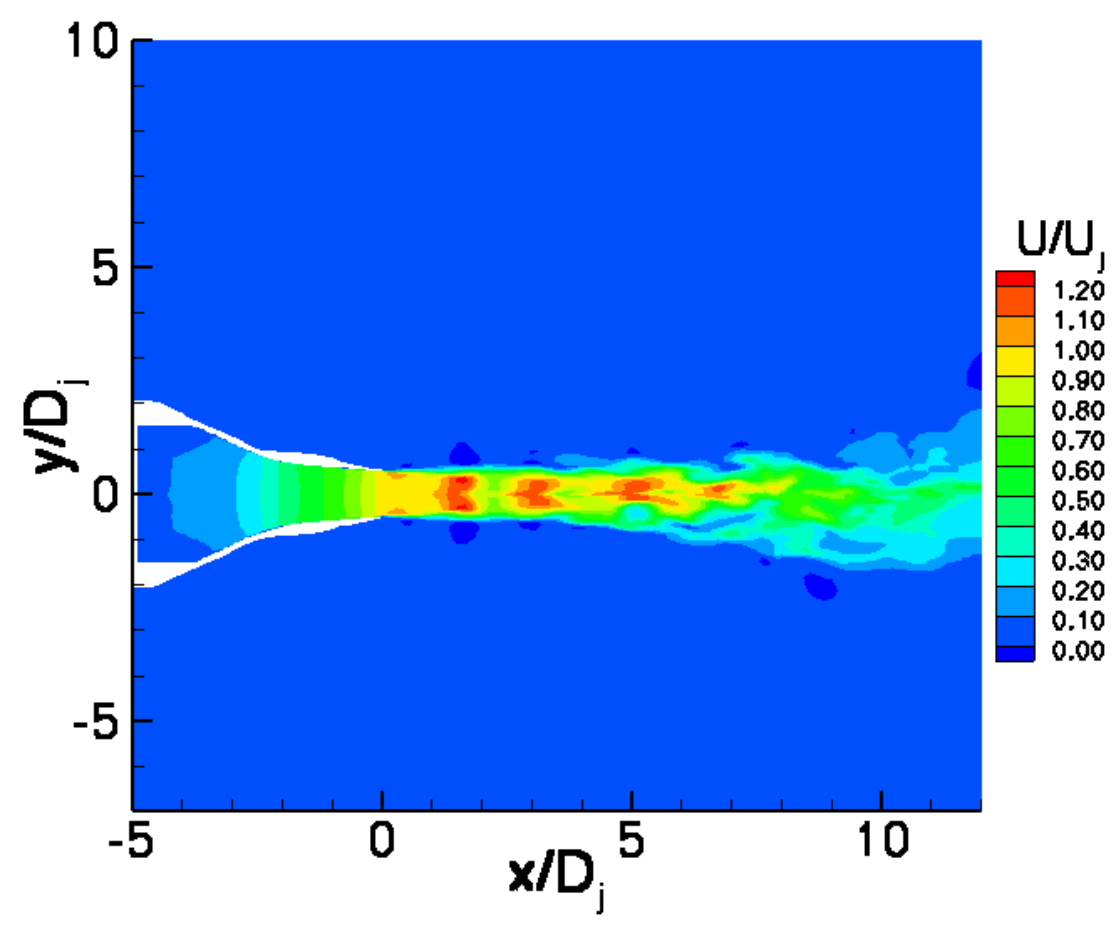

b) Snapshot of Velocity Contour

Figure 12. Single Nozzle Predictions using PANS Formulation Parameter, $\mathrm{f}_{\mathrm{k}}$ Contours Plane. 


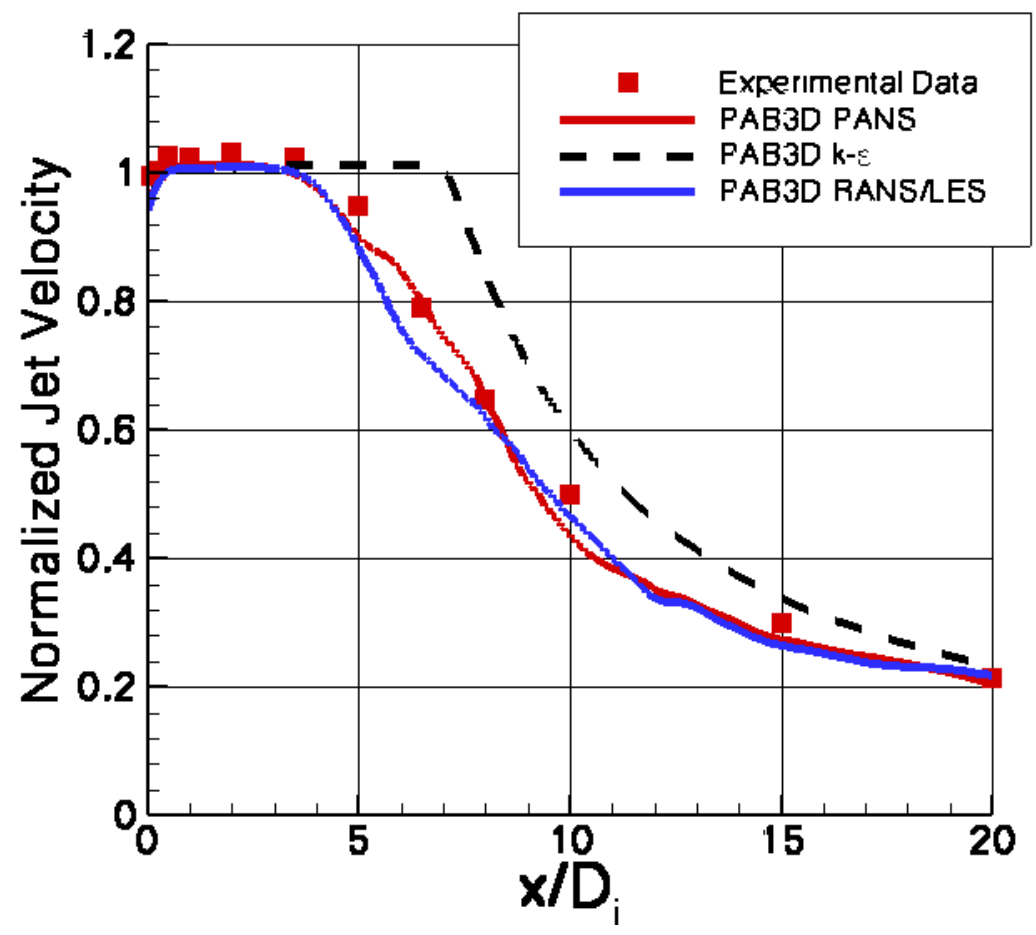

Figure 13. Normalized Jet Centerline Velocity Results using RANS, RANS/LES and PANS Formulations as Compared with Experimental Data.

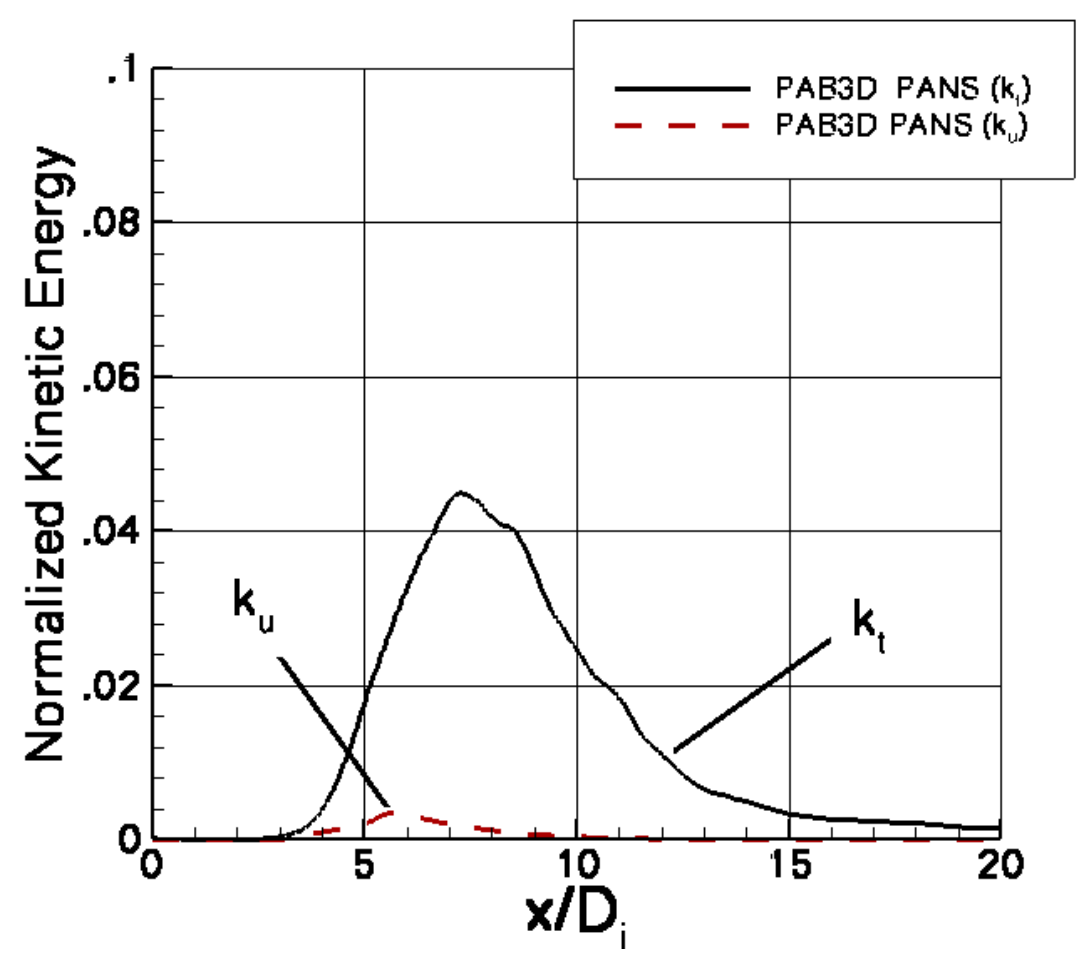

Figure 14. Normalized Unresolved Turbulent Kinetic Energy, $\mathrm{k}_{\mathrm{u}}$ as Compared with Total Kinetic Energy, $\mathrm{k}_{\mathrm{t}}$ using PANS. 